\title{
LA INFLUENCIA DOCENTE EN EL DESARROLLO DEL PENSAMIENTO CRÍTICO COMO UNA HABILIDAD PARA LA VIDA EN NIÑOS, NIÑAS Y ADOLESCENTES CON NECESIDADES EDUCATIVAS ESPECIALES.
}

PAOLA ISLENA FIGUEROA CAÑÓN

TRABAJO DE GRADO PRESENTADO PARA OPTAR AL TÍTULO DE MAGISTER EN PLANEACIÓN PARA EL DESARROLLO

DIRECTORA

ASTRID TIBOCHA

COMUNICADORA SOCIAL

UNIVERSIDAD SANTO TOMAS DE COLOMBIA

DIVISIÓN CIENCIAS SOCIALES

FACULTAD DE SOCIOLOGÍA

MAESTRÍA EN PLANEACIÓN PARA EL DESARROLLO

BOGOTÁ D.C 2016 


\section{RESUMEN}

Las dinámicas educativas se encuentran entrelazadas en un sinfín de procesos administrativos, lecturas y construcción de currículos según los lineamientos del Ministerio de Educación y de la Secretaría de Educación de Bogotá; en este proceso pedagógico las aulas de educación se encuentran conformadas en el Colegio Gustavo Restrepo por tres (3) modalidades de atención aulas de educación regular, aulas con inclusión y aulas de educación especial y diversificadas. El propósito de esta investigación consistió en realizar un análisis de las dinámicas de las aulas exclusivas, centrándose en el rol de las docentes de aulas exclusivas como mediadoras del desarrollo del pensamiento crítico desde las habilidades para la vida, en niños, niñas y adolescentes del ciclo II, III y IV de educación especial.

Este trabajo de investigación se elaboró desde el enfoque cualitativo de tipo analítico, constando de tres (3) fases que permitieron realizar la construcción de los instrumentos de entrevista semiestructurada, recolección de la información y el estudio de las entrevistas desde el enfoque del desarrollo humano integral y su relación con las habilidades para la vida.

El proceso analítico de este escrito está enfocado a estudiar e identificar entre otros aspectos la influencia del docente en el desarrollo del pensamiento crítico como una habilidad para la vida en el marco del proceso pedagógico adaptado a las necesidades de la población de educación especial que asiste a estas aulas, con el fin de identificar estos aspectos o las dificultades presentes frente al tema.

Palabras Claves: Desarrollo Humano Integral, Habilidades para la vida, Aulas exclusivas, pensamiento crítico, escuela. 
INFLUENCIA DOCENTE EN EDUCACION ESPECIAL Y DESARROLLO INTEGRAL 2

\section{SUMMARY}

Educational dynamics are intertwined in a host of administrative processes, readings and construction of curricula according to the guidelines of the Ministry of Education and the Ministry of Education of Bogotá; in this educational process education classrooms they are formed in the Gustavo Restrepo College for three (3) modes of classroom attention regular education classrooms and classrooms including special education and diversified.

The purpose of this research was to conduct an analysis of the dynamics of exclusive classrooms, focusing on the role of teachers in exclusive classrooms as mediators in the development of critical thinking from life skills in children and adolescents cycle II, III and IV of special education.

This research was developed from the qualitative approach to analytical type, consisting of three (3) phases that allowed for the construction of instruments semi-structured interviews, data collection and study of the interviews from the perspective of integral human development and its relationship with life skills.

The analytical process of this paper is aimed to study and identify among others the influence of teachers in the development of critical thinking as a skill for life as part of the educational process adapted to the needs of the population of special education attend these classes, in order to identify these aspects or present difficulties facing the subject.

Keywords: Integral Human Development, Life skills, exclusive classrooms, critical thinking school. 
INFLUENCIA DOCENTE EN EDUCACION ESPECIAL Y DESARROLLO INTEGRAL 3

Tabla de contenido

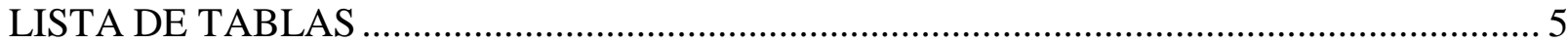

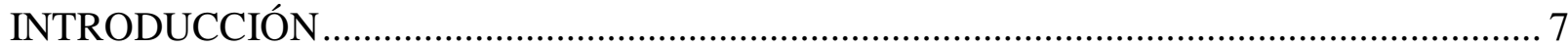

1. CAPITULO ¿LA TRADICIÓN DE HABLAR SOBRE LA EDUCACION ESPECIAL, UNA MIRADA BIOLOGISISTAS, SOCIAL, POLÍTICA O INCLUYENTE? PARA HABLAR DE HABILIDADES PARA LA VIDA DESDE EL PENSAMIENTO CRÍTICO. 18

1.1. Entre la historia social y la parvedad de hablar sobre habilidades para la vida en la población

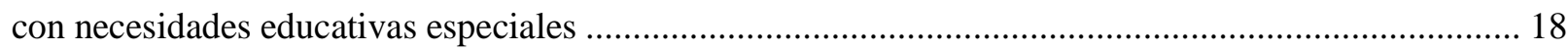

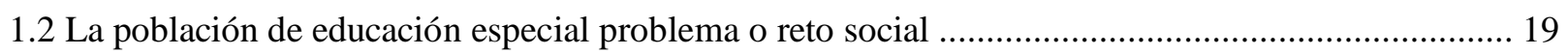

1.3 Del idiota al papel político y social. Los años sesenta y setenta ................................................... 22

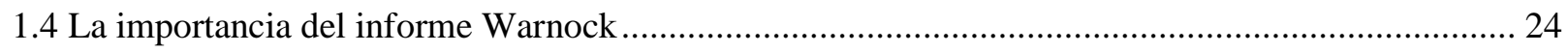

1.5 ¿Y qué sucede con lo cuantificable del Déficit cognitivo? ...................................................... 25

1.6 Políticas públicas de educación especial una mirada a la apuesta en educación ............................. 27

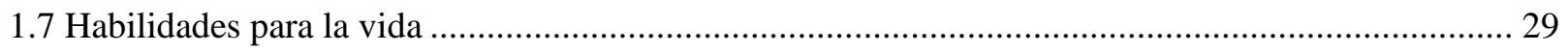

1.8 Desarrollo humano integral su relación con las habilidades para la vida ....................................... 30

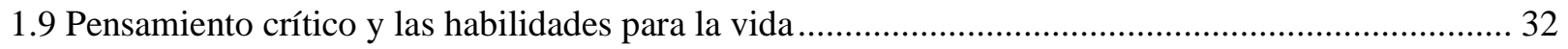

1.9.1 El contexto de la familia como un modelo en el desarrollo de las habilidades para la vida 34

1.9.2 El contexto de la escuela y su rol en el desarrollo humano integral ................................ 36

2. CAPÍTULO. HABILIDADES PARA LA VIDA. EL DESARROLLO DEL PENSAMIENTO CRÍTICO COMO UN FACTOR HUMANO INTEGRAL EN LA POBLACIÓN DE EDUCACIÓN ESPECIAL. DESAFÍOS O TRIVIALIDADES DEL

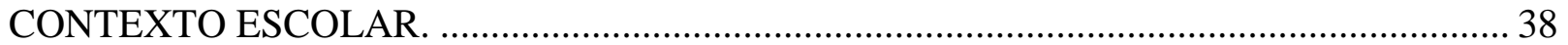

2.1 La importancia de hablar de desarrollo del pensamiento crítico y los currículos ocultos en el

contexto escolar. 38

2.2 El desarrollo del pensamiento crítico como una habilidad para la vida en niños, niñas y adolescentes con necesidades educativas especiales 41

2.3 Niños, niñas y adolescentes de educación especial. 44 


\section{INFLUENCIA DOCENTE EN EDUCACION ESPECIAL Y DESARROLLO INTEGRAL 4}

2.4 Una mirada al pensamiento crítico reflexivo, desde el contexto de la escuela ...................... 44

3. CAPITULO LA INFLUENCIA DEL CONTEXTO ESCOLAR EN EL DESARROLLO DEL PENSAMIENTO CRÍTICO EN NIÑOS, NIÑAS Y ADOLESCENTES

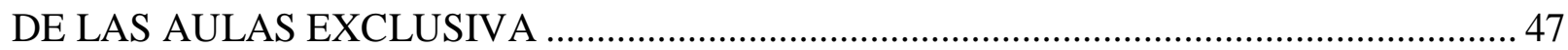

3.1 Análisis de la población docente de las aulas exclusivas .................................................. 47

3.2 Población de estudiantes de las aulas exclusivas ............................................................... 54

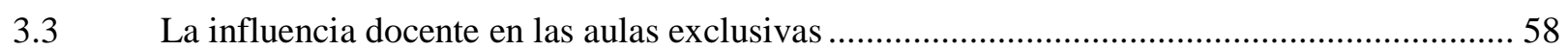

3.4 El contexto de las aulas exclusivas y su relación con las habilidades para la vida y el desarrollo humano integral.

3.5 El desarrollo del pensamiento crítico como una habilidad para la vida en la población perteneciente a las aulas exclusivas o aulas diferenciales. 64

3.6 Entre el contexto escolar y el rol familiar en el desarrollo del pensamiento crítico de los estudiantes pertenecientes a las aulas exclusivas o aulas diferenciales 66

3.7 La relación del déficit cognitivo y el obstáculo para el desarrollo del pensamiento crítico una mirada desde las docentes de educación especial

3.8 La influencia docente en el desarrollo del pensamiento crítico en niños, niñas y adolescentes de aulas exclusivas educación especial, un aspecto del desarrollo humano integral. 72

3.8 El rol de la escuela en el desarrollo del pensamiento crítico de niños, niñas y adolescentes de aulas exclusivas. 75

3.9 La percepción del pensamiento crítico en las aulas exclusivas. 77

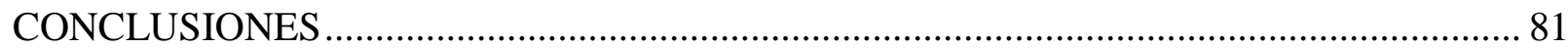

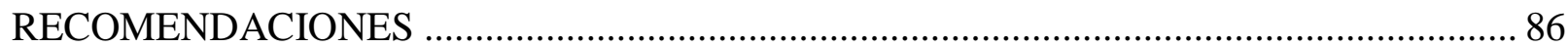

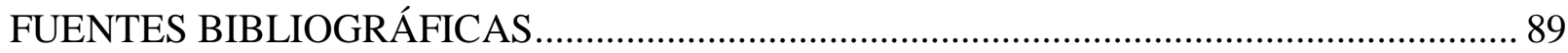

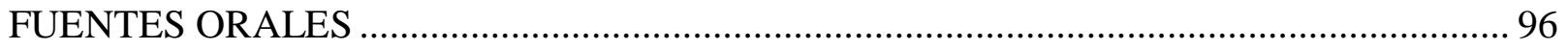


INFLUENCIA DOCENTE EN EDUCACION ESPECIAL Y DESARROLLO INTEGRAL 5

\section{LISTA DE TABLAS}

Pág.

Tabla 1 Organización de categorías para el análisis del trabajo

Tabla 2 Categorías establecidas de discapacidad

Tabla 3 Comparativa de los criterios de diagnóstico DSM 


\section{LISTA DE FIGURAS}

Pág.

Figura 1 Un espacio para reconocer el contexto.

Figura 2 Tiempo laborando como docente en educación especial.

Figura 3 Caracterizaciones niñas, niñas y adolescentes de Educación especial

Sede C, jornada mañana

Figura 4 Localidades de procedencia de los estudiantes de Educación especial

Figura 5 Influencia docente en el desarrollo de los procesos del pensamiento crítico

Figura 6 Un espacio para el desarrollo del pensamiento crítico

Figura 7 De la teoría escolar a la realidad de vida

Figura 8 Percepción docente la influencia del contexto educativo en el desarrollo del pensamiento crítico de niños, niñas y adolescentes de educación especial. 77 Figura 9 Percepción del desarrollo del pensamiento crítico las aulas exclusivas 


\section{INFLUENCIA DOCENTE EN EDUCACION ESPECIAL Y DESARROLLO INTEGRAL 7}

\section{INTRODUCCIÓN}

El Colegio Gustavo Restrepo se encuentra ubicado al sur oriente de la ciudad de Bogotá. Está constituido por cuatro (4) sedes, diferenciadas de acuerdo a la estructura curricular por ciclos de educación; actualmente su organización se encuentra de la siguiente forma: sede A, educación básica secundaria y educación media; sede B, educación inicial y educación básica primaria; sede C, Educación Especial con aulas exclusivas y la sede D, aulas diversificadas, caracterizada por la formación laboral a los y las adolescentes que vienen de educación especial.

En las dinámicas que se presentan en esta institución educativa se encuentra que el programa de educación especial lleva aproximadamente treinta (30) años en los que no se han llevado a cabo cambios curriculares significativos, situación que contrasta con las diversas reformas que se han implementado en la educación a nivel nacional y distrital; a partir de estos aspectos y de la orientación y formación de la autora del presente trabajo de grado, se consideró dar un papel significativo a la formación de habilidades para la vida en los niños, niñas y adolescentes que conforman las aulas exclusivas, así como al rol de las docentes que actualmente se encuentran en ese espacio escolar, con el fin de reconocer la influencia que éstas tienen en el desarrollo del pensamiento crítico de los estudiantes.

Al considerarse este tema bastante complejo y más refiriéndose a la población que hace parte de la educación especializada, es un reto para áreas como la psicología, la educación, la sociología, el trabajo social y la pedagogía entre otras, lograr dilucidar cómo este tipo de procesos se potencializa o no en el contexto escolar de las llamadas aulas exclusivas. Esto, teniendo en cuenta que dicho espacio no es solamente un contexto educativo; además es un espacio de intercambio social e individual en el cual se construyen acuerdos y convivencias; por tal razón y retomando los aspectos anteriores es pertinente indagar cuál es la influencia de las docentes en 


\section{INFLUENCIA DOCENTE EN EDUCACION ESPECIAL Y DESARROLLO INTEGRAL 8}

el desarrollo del pensamiento crítico de niños, niñas y adolescentes con necesidades educativas especiales como un factor de desarrollo humano integral en el Colegio Gustavo Restrepo, sede C, jornada mañana, año 2015.

En el ejercicio de la construcción de los procesos que acompañan las dinámicas sociales, educativas, culturales, familiares e individuales es importante destacar el rol que cumple cada uno de los actores que hacen parte de las mismas, recordando que la planeación dinamiza, entre otros aspectos, la participación activa de cada uno de ellos. Es tal vez por esta razón que reconocer a los miembros de la población con déficit cognitivo, no solamente como actores secundarios y terciarios de las actuaciones administrativas, sociales y políticas sino también como personas que participan y dan sus puntos de vistas, permitirá en el desarrollo de coconstrucción identificar las necesidades reales de esta población.

De acuerdo a lo anterior los parámetros ejercidos desde el contexto de la escuela coadyuvan en el eje de participación, miradas del rol del contexto social, definición de pautas integrales de convivencia, posturas individuales y familiares. Estas categorías hacen parte de los aspectos humanos de la planeación para el desarrollo.

El estudio de investigación busca realizar un análisis descriptivo cualitativo del contexto educativo de las aulas exclusivas del Colegio Gustavo Restrepo como contexto facilitador del acercamiento académico y pedagógico al cual pueden acceder los niños, niñas y adolescentes que presentan déficit cognitivo de leve a moderado; este espacio permitirá caracterizar la influencia que tienen las docentes de educación especializada en el desarrollo del pensamiento crítico de los estudiantes que se encuentran a su cargo.

El propósito de este trabajo es relacionar el concepto de "Habilidades para la vida" desde la categoría de desarrollo del pensamiento crítico y la educación especializada. Para esto, se busca identificar cuál es el rol del contexto educativo en el desarrollo de este tipo de pensamiento, 


\section{INFLUENCIA DOCENTE EN EDUCACION ESPECIAL Y DESARROLLO INTEGRAL 9}

el cual les permite a los niños, niñas y adolescentes fortalecer, aumentar y mantener los elementos necesarios para tomar decisiones sencillas o complejas, así como elementos de autonomía y autoreconocimiento.

Para establecer dicho análisis se explicarán brevemente los conceptos de habilidades para la vida, pensamiento crítico, desarrollo del pensamiento crítico, contexto escolar y educación especializada. Dicha explicación servirá para integrar estos conceptos en los procesos de análisis y lograr establecer diversas conclusiones y recomendaciones que permitan iniciar o fortalecer las estrategias para el desarrollo del pensamiento crítico dentro de las habilidades para la vida de los niños, niñas y adolescentes.

\section{Presentación del problema}

Los escenarios escolares públicos se ven diariamente permeados por los problemas familiares, las dificultades que presentan algunos niños, niñas y adolescentes en el aprendizaje, la informalidad en la presentación personal, la falta de cumplimiento en las normas al interior del plantel educativo, el incumplimiento en los estándares de educación y la planeación correspondiente a los períodos académicos por parte de las docentes entre otros aspectos no menos relevantes.

Sin embargo, aunque se plantea que al interior de los escenarios educativos es importante generar acciones encaminadas al desarrollo socio-afectivo integral y a la construcción de ciudadanía, es pertinente recalcar que para el caso de los estudiantes, familias y docentes de las aulas exclusivas o aulas integradas por niños, niñas y adolescentes de los ciclos I, II y III del Colegio Gustavo Restrepo, sede C, es complejo el reconocimiento y la identificación de estos procesos; esta situación se presenta debido a que las influencias familiares y escolares como 


\section{INFLUENCIA DOCENTE EN EDUCACION ESPECIAL Y DESARROLLO INTEGRAL 10}

agentes facilitadores no se encuentran significativamente potencializadas en el proceso educativo ni claramente especificadas como labor conjunta entre la familia y el contexto de la escuela.

De acuerdo a lo anterior, es importante reconocer el papel del contexto escolar en la consolidación de habilidades y aptitudes para la vida, retomando a Berger y Luckmann (2001: 164). La sociedad brinda al sujeto las herramientas requeridas para que éste logre comprender el entramado dialéctico con el que diariamente se relaciona, aprehende e interpreta desde la cultura en la cual se desarrolla, así como el significado de las diferentes situaciones en las cuales se ve inmerso; por ende, el espacio escolar se convierte en un facilitador de la construcción e instauración de las expresiones, tanto psicológicas como artísticas, de valores y por supuesto en la construcción del pensamiento y de los procesos de aprendizaje escolar.

Con este estudio se busca comprender cuál es la influencia de las docentes, en el desarrollo del pensamiento crítico de niños, niña y adolescente con necesidades educativas especiales, partiendo del estudio de caso del Colegio Gustavo Restrepo, sede C José Acevedo y Gómez, ubicado en la Localidad 18 Rafael Uribe, Barrio San José en Bogotá.

Desde esta perspectiva es importante tener en cuenta que cuando se habla del pensamiento crítico durante esta investigación se plantea como una categoría enmarcada en las habilidades para la vida. Se piensa en esta categoría como una que le permite a la población de niños, niñas y adolescentes la construcción de posibilidades y la toma de decisiones frente al contexto diario en el cual se ven involucrados los estudiantes de la sede José Acevedo y Gómez de las aulas exclusivas; es así como este estudio de investigación, se ha encuadrado desde la mirada del desarrollo humano integral relevante en los procesos sociales, humanos, psicológicos, políticos y culturales de los cuales los diferentes actores de esta investigación hacen parte en el diario vivir. 


\section{INFLUENCIA DOCENTE EN EDUCACION ESPECIAL Y DESARROLLO INTEGRAL 11}

De acuerdo a lo anterior este documento de investigación se esboza desde una mirada integral, buscando dar significado a los planteamientos del desarrollo humano integral, desde el reconocimiento y la inclusión, como lo refiere en sus apartes la política pública de infancia y adolescencia en Colombia; en los procesos de enseñanza, aprendizaje e intercambio de experiencias en los diferentes contextos donde los niños, niñas y adolescentes están en una constante búsqueda colectiva de los hábitos, las costumbres, las creencias, sentando las bases para la construcción de una cultura a favor de los niños, las niñas y los adolescentes; desde la garantía de los derechos para ir más allá de la visión sectorial fragmentada y así fortalecer la reorganización en función del reconocimiento integral del sujeto, donde se identifiquen los territorios sociales como escenarios en los cuales se pueda movilizar la calidad de vida y la participación.

La propuesta de investigación se realizará con nueve (9) docentes del Colegio Gustavo Restrepo, sede C José Acevedo y Gómez, jornada mañana, de la ciudad de Bogotá, quienes por desempeñarse en cargos pronunciados desde la Secretaría de Educación del Distrito se denominan docentes.

De las nueve (9) docentes seis (6) docentes se encuentran capacitadas en educación especial y encargadas de los curso 201, 401, 402, 501, 601, 602; y tres (3) son profesionales formadas en Terapia del Lenguaje, Terapia Ocupacional y Trabajo Social, capacitadas para desempeñar desde su área de especialidad el trabajo acorde a las necesidades de los estudiantes de educación especial así como el trabajo y apoyo a las docentes de las aulas de educación especial o aulas exclusiva. Así mismo, se tendrán en cuenta fuentes secundarias que permitirán aportar mayor información para la investigación y análisis que se está desarrollando, dentro y que hacen parte de la Secretaría de Educación Distrital.

\section{Los objetivos de la investigación}




\section{INFLUENCIA DOCENTE EN EDUCACION ESPECIAL Y DESARROLLO INTEGRAL 12}

El objetivo general de este trabajo de investigación es, entonces, realizar un análisis de la influencia de las docentes en el desarrollo de habilidades para la vida a partir del pensamiento crítico, de niños, niñas y adolescentes con necesidad exclusivas del Colegio Gustavo Restrepo, sede C José Acevedo y Gómez, ubicado en la Localidad 18 Rafael Uribe Uribe, Barrio San José Obrero en Bogotá.

Teniendo en cuenta este objetivo, se busca desarrollar los siguientes objetivos específicos, a saber:

- Indagar frente al rol que las posturas teóricas han desempeñado a la luz del desarrollo del pensamiento crítico de niños, niñas y adolescentes con necesidades educativas especiales.

- Identificar la influencia del contexto escolar en el desarrollo del pensamiento crítico de niños, niñas y adolescentes con necesidades educativas especiales.

- Caracterizar las aulas exclusivas, como escenarios significativos en el desarrollo del pensamiento crítico en los niños, niñas y adolescentes de aulas exclusivas.

\section{El método de trabajo}

Esta investigación se llevó a cabo desde la metodología de acción participativa como técnica que permite al investigador ser parte integral tanto en la ejecución e implementación de la estrategia como en la retroalimentación de los resultados esperados. De este modo, se enmarcó el estudio en un enfoque cualitativo de tipo analítico; durante el proceso de investigación se contó con la aplicación de instrumentos como entrevistas semiestructuradas, teniendo como punto de fortalecimiento el intercambio de ideas en el aula y las dinámicas propias del contexto educativo. A partir de este proceso se identifican las categorías que se mostrarán a continuación: 
INFLUENCIA DOCENTE EN EDUCACION ESPECIAL Y DESARROLLO INTEGRAL 13

Tabla 1 Organización de categorías para el análisis del trabajo

\begin{tabular}{|c|c|c|}
\hline CATEGORÍA & SUBCATEGORÍA & DESCRIPTOR \\
\hline La escuela & Influencia docente & $\begin{array}{l}\text { - } \text { Estrategias pedagógicas } \\
\text { - Relación académica y social } \\
\text { - Percepciones acerca del pensamiento } \\
\text { crítico en niños, niñas y adolescentes } \\
\text { con déficit cognitivo }\end{array}$ \\
\hline $\begin{array}{l}\text { Desarrollo humano } \\
\text { integral }\end{array}$ & Pensamiento crítico & $\begin{array}{l}\text { - Habilidades para la vida } \\
\text { - Interrelación con el contexto psicosocial } \\
\text { e individual. }\end{array}$ \\
\hline Educación especial & Aulas exclusivas & $\begin{array}{l}\text { - Coeficiente intelectual } \\
\text { - Capacidades } \\
\text { - Aprendizaje }\end{array}$ \\
\hline
\end{tabular}

Las fuentes secundarias se tuvieron en cuenta ya que estos son datos que existen y han sido publicados y en esa medida contribuyen a la investigación que se va a realizar. En ese orden de ideas, se accedió a la revisión de los documentos desarrollados desde la Secretaría de Educación del Distrito, el Departamento de Inclusión de la misma secretaría y los documentos elaborados por las docentes entre otros aspectos.

El desarrollo de esta investigación permite realizar un análisis a los procesos llevados a cabo por las docentes en las aulas exclusivas desde la mirada de un desarrollo humano integral. Tal como lo plantea Barroso (2012), se trató de realizar una aproximación (fundamentalmente cifrada) a la realidad del contexto de investigación; este primer acercamiento a la realidad social y las dinámicas permite una ubicación conceptual e investigativa, fortaleciendo de alguna forma el hilo conductor que como refiere Barroso (2012). Asimismo, fortalece la función de observación sistematizada en la investigación. 


\section{INFLUENCIA DOCENTE EN EDUCACION ESPECIAL Y DESARROLLO INTEGRAL 14}

De igual forma para el proceso de investigación, fue importante trabajar desde la mirada de la participación-observación ya que ésta permite tener un mayor acercamiento a la lectura del problema de investigación propuesto. Según León y Montero (2002), referenciados por Martínez (2007), "la participación pone el énfasis en la experiencia vivida por el investigador apuntando su objetivo a "estar dentro "de la sociedad estudiada". De acuerdo a lo anterior, estar dentro constituye al investigador como parte de la población estudiada y, en esa medida, encontrarse también en el problema analizado, facilitando al investigador tener mayor acceso a la información que se desarrolla en el contexto investigado.

"Ello no quiere decir que la subjetividad es una caja negra que no se puede someter a análisis” León y Montero (2002). De acuerdo a lo anterior, se construyó como herramienta de apoyo para la recolección de información la entrevista semiestructurada a profundidad, facilitando una interacción entre el sujeto investigador y los actores que hicieron parte de la temática de investigación. La idea de construir una entrevista semidirigida se planteó teniendo en cuenta que este tipo de instrumentos permite un diálogo más espontáneo que de alguna forma invita al entrevistado a posibilitar un espacio de concentración y atención al tema trabajado.

De esa forma, esta entrevista permite la construcción de una narrativa desde la experiencia de saberes de las diferentes docentes que hicieron parte subjetiva, profesional y personal del desarrollo de cada una de las preguntas desarrolladas durante el espacio narrativo. Como lo refiere Valles (1996), enunciado por Castellón (2007), la importancia de tener diferentes métodos y técnicas de análisis, que permitan analizar un mismo problema o tema de investigación, fortalece el desarrollo de la triangulación de la información recogida en los diferentes momentos y espacios, de la triangulación llevan a permitirle acceder al investigador a fortalecer aún más los resultados. 


\section{INFLUENCIA DOCENTE EN EDUCACION ESPECIAL Y DESARROLLO INTEGRAL 15}

De acuerdo a lo anterior, con los insumos logrados con las entrevistas semiestructuradas se realizó el proceso de triangulación y análisis de la información.

\section{Antecedentes de la investigación}

En el mes de noviembre del año 2013, a partir de la convocatoria de becas abierta por la Secretaría de Educación del Distrito de Bogotá, se planteó como proceso de investigación el proyecto que llevaba como título "La familia y la Escuela como contextos facilitadores en el aprendizaje y la participación sociocultural de niños y niñas". Allí se desarrolló como pregunta de investigación la siguiente: ¿Cómo fortalecer los procesos de participación sociocultural en niños y niñas, desde la familia y la escuela? Esta línea de investigación se enmarca a partir de los escenarios escolares del colegio Entre Nubes Sur Oriental. En ese proyecto mencionado, se planteaba la necesidad de tal fortalecimiento desde el proceso pedagógico y psicosocial que se desarrollaba al interior del plantel educativo, antes de pensarse en las categorías que hacían aprobar el curso a los estudiantes. Para este efecto, era determinante reconocer en cada uno de ellos y ellas las habilidades, capacidades y actitudes frente al ámbito escolar, la vida y cómo se encuentran conformados su contexto social, familiar y afectivo.

Como segundo aspecto determinante en la reprobación escolar, entrarían los aspectos de origen psicosocial y las categorías que incluyen a la familia considerando los problemas que se viven dentro de ella, los cuales están directamente relacionados con el desempeño académico, afectivo y personal de cada uno de los niños y niñas.

De acuerdo a las dinámicas, desde la mirada de la investigadora faltaba establecer al interior de los núcleos familiares la importancia del acompañamiento significativo de los padres, madres, abuelos, hermanos, tíos, etc., en el proceso académico, lo cual, de alguna forma, sirve como puente para iniciar los procesos de participación educativa y social, pues el aspecto 
pedagógico que se desarrolla en el salón de clases debe trascender de las paredes del plantel educativo.

Por los temas tratódos anteriormente, se ve la necesidad de adelantar investigaciones sobre temas concretos que logren trascender el aprendizaje del aula y aborden directamente el ejercicio de participación, promoción y validación de los espacios que coadyuven en la formación de niños y niñas proyectados al desarrollo de estrategias desde la escuela hacia el espacio social de participación.

Frente a esta propuesta de investigación se genera un interés directo en el trabajo con la infancia y los aspectos educativos; durante el primer semestre del año 2014, se revisa la elaboración de los objetivos de investigación desarrollados a finales del año 2013, revisión en la cual se determina que los mismos deben ser aún más delimitados y que el título debe cambiar y delimitar las categorías como contexto sociocultural, infancia y escuela.

\section{Población que apoyó la investigación}

La propuesta de investigación se realizó con nueve (9) docentes del Colegio Gustavo Restrepo sede C José Acevedo y Gómez jornada mañana, de la ciudad de Bogotá, quienes por desempeñarse en cargos emitidos desde la Secretaría de Educación del Distrito se denominan docentes. No obstante, a la hora de discriminar los cargos a ocupar se identifican como seis (6) docentes capacitadas en educación especial y tres (3) profesionales direccionadas en Fonoaudiología, Terapia Ocupacional y Trabajo Social, encargadas de desempeñarse desde su área de especialidad con los estudiantes de educación especial y el trabajo y apoyo a las docentes de las aulas exclusivas.

A continuación se presenta el documento elaborado. El mismo se organizó en tres capítulos en los cuales se abordan respectivamente los planteamientos sobre educación especial 
INFLUENCIA DOCENTE EN EDUCACION ESPECIAL Y DESARROLLO INTEGRAL 17

y las concepciones teóricas. En el segundo capítulo se desarrollan los elementos del pensamiento crítico como una habilidad para la vida de la población en referencia a su educación sexual y a su educación especial. Finalmente, en el tercer capítulo se desarrolla el análisis a partir de la información recolectada. 


\section{CAPITULO ¿LA TRADICIÓN DE HABLAR SOBRE LA EDUCACION ESPECIAL, UNA MIRADA BIOLOGISISTAS, SOCIAL, POLÍTICAO INCLUYENTE? PARA HABLAR DE HABILIDADES PARA LA VIDA DESDE EL PENSAMIENTO CRÍTICO.}

\subsection{Entre la historia social y la parvedad de hablar sobre habilidades para la vida en la población con necesidades educativas especiales}

La infancia como una de las etapas del ciclo vital, es uno de los momentos significativos que le permitirá al ser humano la continuación y afianzamiento de las capacidades y potencialidades para enfrentar, construir y generar en cualquiera de los contextos sociales donde se encuentre, las herramientas requeridas para identificar y reconocer las dinámicas presentes en estos contextos. Para la OMS estos elementos se encuentran delimitados de acuerdo a la lectura de necesidades sociales o individuales, de las cuales hacen parte los individuos de determinado contexto (Organización Mundial para la Salud, 1993).

Según Berger y Luckmann (2001, p.166): "la socialización secundaria es cualquier proceso posterior a la niñez que induce al individuo ya socializado a nuevos sectores del mundo objetivo de su sociedad". Es a partir de este momento en el que el reconocimiento del aspecto educativo permitirá al niño o niña, reconocerse a sí mismo, reconocer al otro y empezar a definir cuál es su papel en el contexto social, de acuerdo a la mirada individualidad y al rol papel como actor social.

Teniendo en cuenta la postura de los dos autores anteriores, es clave examinar y comprender durante el proceso del desarrollo humano integral de los niños, niña y adolescentes que estos son actores políticos, inter-sociales, afectivos, individuales y aprendices directos e indirectos de todo aquello que la familia, la escuela y sus iguales les brindan.

De la misma manera, es importante reconocer el planteamiento desarrollado por la OMS durante el año 2011 sobre las habilidades para la vida como estrategias que permiten el desarrollo 
de las destrezas psicosociales. Éstas le dan a las personas herramientas para afrontar en forma práctica los requerimientos de la vida diaria de modo que los diferentes actores sociales generen a futuro una afectación colectiva de los hábitos, las costumbres, las creencias y las bases para la resolución de conflictos, la comunicación asertiva, el desarrollo de un pensamiento crítico y creativo entre otros elementos que hacen parte de la construcción de habilidades para la vida.

\subsection{La población de educación especial problema o reto social}

Las bases de la educación especial se encuentran en los estudios realizados por el francés Jean Marc Gaspard Itard, que en los albores de su carrera desarrolló su trabajo educativo con sordomudos e investigativo con alumnos que presentaban diversas deficiencias sensoriales (Castejón, 2000).

Fue así como durante la primera parte del siglo XX, predomina el significado de deficiencia, disminución o hándicap relacionado con la Educación Especial, de acuerdo a Marchesi y Martín (Citados por Castejón, 1990). Estas deficiencias se consideran además determinadas por factores innatos difícilmente modificables, ya que para ese entonces la presencia de la discapacidad se daba principalmente por causas orgánicas, las cuales se producían durante los primeros meses de desarrollo y que eran difícilmente modificables posteriormente (Marchesi 1999).

Lo procesos para tratar de identificar y reconocer las diferencias de las personas que presentaban un déficit o trastornos en el aprendizaje llevó a la realización de diferentes trabajos con el fin de categorizar los posibles trastornos relacionados al déficit (ver tabla 2); sin embargo, frente a esta postura de corte desarrollista, se observaba que los elementos eran inherentes a los niños, situación que dejaba a un lado la posibilidad de realizar procesos de intervención a nivel escolar o de cambio. 


\section{INFLUENCIA DOCENTE EN EDUCACION ESPECIAL Y DESARROLLO INTEGRAL 20}

Ello trajo consigo dos consecuencias, a saber: por un lado la necesidad de determinar de forma precisa el déficit o trastorno, para lo que se emplean los test de inteligencia, como los empleados por Galton y Binet, referidos por Castejón (2000); es decir, instrumentos psicotécnicos que permiten identificar y clasificar cuantitativamente los distintos niveles y categorías del retraso mental. Como segunda medida, la necesidad de reconocer la importancia de desarrollar una atención educativa de los alumnos que presentaban alguna disminución o retraso y que por tal motivo requerían una atención diferente en centros educativos específicos (Marchesi, 1999).

Teniendo en cuenta lo anterior, se comienza a incentivar la estructura de centros de enseñanza específicos para la población que presentaba estas características, surgiendo así las escuelas de educación especial; hacia los años cuarenta y cincuenta se empieza a suscitar un giro de la mirada hacia la población de educación especial, llevando con ello la posibilidad de observar no solamente la incurabilidad del trastorno y sus mediciones cuantitativas, sino también la posibilidad de incorporar en la mirada del retraso mental las influencias del contexto social y cultural los cuales pueden determinar un funcionamiento intelectual más deficiente (Marchesi, 1999).

Con estos aspectos se abre la posibilidad de revisar otros elementos presentes en las situaciones donde se evidencia retraso intelectual incluyendo en esta revisión elementos como la estimulación adecuada, procesos de aprendizaje incorrectos, adaptación social entre otros abriendo la puerta a la posibilidad de intervención con la población perteneciente a las aulas de educación especial. 
INFLUENCIA DOCENTE EN EDUCACION ESPECIAL Y DESARROLLO INTEGRAL 21

Tabla 2 Categorías establecidas de discapacidad

\begin{tabular}{|c|c|c|c|}
\hline 1886 & 1899 & 1913 & 1945 \\
\hline Idiota & Idiota & Idiota & Subnormal severo \\
\hline Imbécil & $\begin{array}{l}\text { Imbécil } \\
\text { Ciego } \\
\text { Sordo } \\
\text { Epiléptico } \\
\text { Deficiente }\end{array}$ & $\begin{array}{l}\text { Imbécil } \\
\text { Imbécil moral, } \\
\text { Ciego } \\
\text { Sordo } \\
\text { Epiléptico } \\
\text { Deficiente mental, } \\
\text { Deficiente físico. }\end{array}$ & $\begin{array}{l}\text { Ciego } \\
\text { Ambliope } \\
\text { Sordo } \\
\text { Hipoacúsico } \\
\text { Epiléptico } \\
\text { Subnormal } \\
\text { educable } \\
\text { Inadaptado } \\
\text { Disminuido } \\
\text { físico, Defecto } \\
\text { habla, delicado, } \\
\text { diabético. }\end{array}$ \\
\hline 1962 & 1970 & \multicolumn{2}{|l|}{1981} \\
\hline Subnormal severo & $\begin{array}{l}\text { Subnormal educable } \\
\text { (severo) }\end{array}$ & \multicolumn{2}{|c|}{$\begin{array}{l}\text { Niño con dificultades de aprendizaje } \\
\text { (severo) }\end{array}$} \\
\hline Psicopático & $\begin{array}{l}\text { Ciego } \\
\text { Ambliope } \\
\text { Sordo }\end{array}$ & \multicolumn{2}{|l|}{$\begin{array}{l}\text { Ciego } \\
\text { Ambliope } \\
\text { Sordo }\end{array}$} \\
\hline Hipoacúsico & $\begin{array}{l}\text { Hipoacúsico } \\
\text { Epiléptico Subnormal } \\
\text { educable (ligero o } \\
\text { moderado) } \\
\text { Inadaptado } \\
\text { Necesidades } \\
\text { educativas especiales } \\
\text { Disminuido físico } \\
\text { Defecto habla }\end{array}$ & \multicolumn{2}{|c|}{$\begin{array}{l}\text { Hipoacúsico } \\
\text { Epiléptico } \\
\text { Niño con dificultades de aprendizaje (ligero } \\
\text { o moderado) } \\
\text { Inadaptado, alterado } \\
\text { Disminuido físico, } \\
\text { Defecto habla. }\end{array}$} \\
\hline
\end{tabular}


INFLUENCIA DOCENTE EN EDUCACION ESPECIAL Y DESARROLLO INTEGRAL 22

\begin{tabular}{|l|l|l|}
\hline Delicado & Delicado & Delicado \\
& ¿Disléxico? & \\
& ¿Autista? & \\
\hline
\end{tabular}

Fuente: Tomado de Marchesi, A. (1999), quien retomó a De Tomlimson (1982).

\subsection{Del idiota al papel político y social. Los años sesenta y setenta}

Durante los años sesenta y setenta, se da inicio al nacimiento de movimientos sociales que de alguna manera impulsan cambios en el contexto de la educación especial. Estos cambios se pueden resumir en los siguientes diez puntos fundamentales para concepción de la actual mirada frente al tema de la educación especial (Marchesi, 1999).

1. Una nueva concepción de los trastornos del desarrollo y de la deficiencia: Al plantearse el déficit, esta categoría pasa de ser un elemento puramente clínico a una categoría relacionada con la función que en la experiencia educativa puede tener el estudiante. El sistema educativo puede, por tanto, intervenir para favorecer el desarrollo y el aprendizaje de los alumnos con alguna característica «deficitaria», según Marchesi (1999, p.25).

2. Una nueva mirada de los procesos de aprendizaje y de las diferencias individuales:

Desde este aspecto se tienen en cuenta de forma integral las nuevas teorías del desarrollo y del aprendizaje, las cuales direccionan su mirada a la interacción de los sujetos con el contexto, rezagando la mirada puramente biologisistas. Se reconoce el papel activo del estudiante y la importancia de que los profesores reconozcan y tengan en cuenta el nivel inicial de conocimientos y le ayuden a mejorarlos o a reconstruirlos.

3. La revisión de la evaluación psicométrica: Si bien las pruebas psicométricas sirven como una herramienta para conocer la capacidad de aprendizaje de las personas y en este caso de los estudiantes, frente a este aspecto se logra dejar en una segunda instancia esta herramienta para dejar a un lado la clasificación numérica de los estudiantes. Siendo así las cosas, se les 


\section{INFLUENCIA DOCENTE EN EDUCACION ESPECIAL Y DESARROLLO INTEGRAL 23}

confiere a las escuelas un papel más influyente en los cambios efectivos de los estudiantes así como la potencialización de aprendizaje con la participación de otros profesionales.

4. Mayor presencia de profesores competentes: En este punto, las organizaciones sociales buscaron fortalecer el sistema de formación de los maestros que desarrollaban su quehacer con la población de educación especial y mejorar su preparación pedagógica.

5. La extensión de la educación obligatoria: Desde esta mirada se plantea la necesidad de que las escuelas de educación regular aprendan a identificar que los alumnos asistentes también presentan diferencias entre ellos, de tal forma que se busca replantear la generalización del contexto escolar, el cual debe ser integrador y no segregador a nivel de básica y secundaria.

6. El abandono escolar: De acuerdo a este aspecto, se requiere incentivar en los estudiantes y las familias la importancia de terminar los estudios. La preocupación es considerable, teniendo en cuenta que para ese momento hay un número significativo de estudiantes que abandonan la escuela antes de finalizar la educación obligatoria o no terminan con éxito sus estudios básicos Según Marchesi (1999, p.26).

7. La evaluación de las escuelas de educación especial: Se presentan bajos resultados de las escuelas de educación especial, frente a este aspecto se vuelve a pensar en la posibilidad escolarizar a aquellos estudiantes que no presentan una afectación grave en el desarrollo de los elementos de integración social.

8. Las rutinas positivas de integración: Se da inicio a los procesos de integración en los cursos de aula regular contando con el apoyo de los diferentes de los sectores y de la administración educativa, fortaleciendo la perspectiva de la integración en el aula.

9. La presencia de un contexto normalizador en el enfoque de los servicios sociales: Desde esta perspectiva se buscó que los contextos médicos, psicológicos, escolares y en general los servicios sociales, brindaran un servicio por igual a todas las personas que requirieran del mismo, 


\section{INFLUENCIA DOCENTE EN EDUCACION ESPECIAL Y DESARROLLO INTEGRAL 24}

con este aspecto el sistema de atención no permite la existencia de un sistema paralelo de atención diferente a quienes lo requieran.

10. Los diferentes movimientos sociales: Se presenta y fortalece la presencia de grupos sociales a favor de la igualdad, los derechos de las minorías y su papel en la sociedad. Con este aspecto se impulsa el cambio a la transformación de nuevas miradas frente a las diferentes variables que se encuentran presentes en la población con discapacidad y el rol del contexto escolar como un elemento integrador, tanto en los profesores como en la sociedad a la cual pertenece.

\subsection{La importancia del informe Warnock}

Hacia el año 1974, desde la Secretaria de Educación del Reino Unido, teniendo en cuenta el concepto de necesidades educativas especiales que se había comenzado a utilizar desde los años setenta, emite el informe desarrollado por expertos presididos por Mary Warnock donde plantean algunos aspectos como: "Al agruparse las dificultades en términos de categorías puntualizas este aspecto no es beneficioso ni para los niños, ni para los maestros, ni para los padres" (Marchesi, 1999, p.27). Lo anterior, teniendo en cuenta que se evidencian cuatro razones fundamentales:

$\checkmark$ Se encuentra que muchos niños están afectados por varias discapacidades

$\checkmark$ Las categorías tienden a confundir qué tipo de educación especial es necesaria, ya que este aspecto tiende a promover la idea que todos los niños que están en una misma categoría tienen equivalentes necesidades educativas.

$\checkmark$ Las llamadas categorías cuando sirven como base para el suministro de recursos, no los proporcionan a aquellos niños que no se ajustan a las categorías establecidas.

$\checkmark$ Las categorías ocasionan el efecto de etiquetar a los niños de forma negativa. 


\section{INFLUENCIA DOCENTE EN EDUCACION ESPECIAL Y DESARROLLO INTEGRAL 25}

Con este informe se plantea el requerimiento de hablar de necesidades educativas especiales para determinar las necesidades específicas a cada una de las problemáticas presentadas en el salón de clase así como el reconocimiento de los derechos de los niños y niñas que presentan un déficit cognitivo. A partir de este aspecto se logra afectar de forma positiva a un continuo de estudiantes, este informe refiere la necesidad de hablar de formas de integración de la población con necesidades educativas especiales distinguiendo tres formas, a saber: la integración física con referencia al espacio de infraestructura que comparten los estudiantes de educación regular y especial, pero que mantienen una organización independiente; la integración social donde se surgen espacios de encuentro en las actividades del diario vivir y finalmente la integración funcional donde los estudiantes de educación especial comparten de forma parcial o completa con el contexto de aula regular, reconociendo su rol en ese espacio social y educativo.

\section{5 ¿Y qué sucede con lo cuantificable del Déficit cognitivo?}

En el Manual DSM IV, que antecede al actual, se planteaba la definición de retraso mental, el cual se encontraba definido en la categoría de Trastornos de inicio de la infancia y la adolescencia. En la actualidad este Manual ha sido actualizado con el DSM V, el cual plantea la categoría anterior en Trastornos del Neurodesarrollo y la subcategoría de Discapacidades intelectuales.

Teniendo en cuenta los nuevos parámetros establecidos no sólo desde la mirada académica y pedagógica, sino también desde el Manual Diagnóstico y Estadístico de los Trastornos Mentales DSM V, como bitácora para encontrar nuevas miradas frente a los trastornos cognitivos, se encuentra que actualmente hablamos de Discapacidades intelectuales (Discapacidad intelectual, Retraso global del desarrollo y discapacidad intelectual No especificada). Para el proceso de evaluación de éste no solamente se tiene en cuenta el concepto 
de coeficiente intelectual, es decir, el parámetro cuantitativo, sino a su vez las capacidades y habilidades que los niños, niñas y adolescentes desarrollan en los entornos sociales, comunicativo e individual (2014, p.19).

TABLA 3 Comparativa de los criterios de diagnóstico DSM

\begin{tabular}{|c|c|}
\hline $\begin{array}{c}\text { DSM IV(APA 2002) RETRASO } \\
\text { MENTAL }\end{array}$ & $\begin{array}{c}\text { DSM } 5 \text { (APA 2013) DISCAPACIDAD } \\
\text { INTELECTUAL (TRASTORNO } \\
\text { INTELECTUAL DEL DESARROLLO) }\end{array}$ \\
\hline $\begin{array}{l}\text { A. Capacidad intelectual significativamente } \\
\text { inferior al promedio: un C.I de } 70 \\
\text { inferiores en un test de C.I administrado } \\
\text { individualmente, (en el caso de niños } \\
\text { pequeños, un juicio clínico de capacidad } \\
\text { intelectual significativamente inferior al } \\
\text { promedio }\end{array}$ & $\begin{array}{l}\text { A. Déficits en el funcionamiento intelectual, } \\
\text { en aspectos como razonamiento, solución } \\
\text { de problemas, planificación, pensamiento } \\
\text { abstracto, toma de decisiones, aprendizaje } \\
\text { académico y aprendizajes a través de la } \\
\text { propia experiencia, confirmado por } \\
\text { evaluaciones clínicas a través de test de } \\
\text { inteligencia estandarizados aplicados } \\
\text { individualmente. }\end{array}$ \\
\hline $\begin{array}{l}\text { B. Déficits o alteraciones concurrentes de la } \\
\text { actividad adaptativa actual (estos es, la } \\
\text { eficacia de la persona para satisfacer las } \\
\text { exigencias planteadas para su edad y por } \\
\text { su grupo cultural), en por lo menos dos de } \\
\text { las áreas siguientes: comunicación, } \\
\text { cuidado personal, vida doméstica, } \\
\text { habilidades sociales/interpersonales, } \\
\text { utilización de recursos comunitarios, } \\
\text { autocontrol, habilidades académicas } \\
\text { funcionales, trabajo, ocio, salud y } \\
\text { seguridad. }\end{array}$ & $\begin{array}{l}\text { B. Los déficits en el funcionamiento } \\
\text { adaptativo que resultan en la no consecución } \\
\text { de los estándares sociales y culturales para la } \\
\text { independencia personal y las } \\
\text { responsabilidades sociales. Sin el } \\
\text { consiguiente apoyo, los déficits adaptativos } \\
\text { limitan el funcionamiento en una o más } \\
\text { actividades de la vida diaria, tales como la } \\
\text { comunicación, la participación social, y la } \\
\text { vida independiente, a través de múltiples } \\
\text { entornos, tales como la casa, la escuela, el } \\
\text { trabajo y la comunidad. }\end{array}$ \\
\hline
\end{tabular}


INFLUENCIA DOCENTE EN EDUCACION ESPECIAL Y DESARROLLO INTEGRAL 27

C El inicio es anterior a los 18 años

Fuente: Tomado Guía de Consulta de los criterios de diagnóstico del DSM 5 (2014).

Con estos cambios generados desde la perspectiva clínica y psicométrica, se permite reconocer que los procesos cognitivos, se acompañan de espacios de intercambio social, estrategias de adaptación, reconocimiento del contexto y la identificación del sujeto en un espacio social y cultural Vygotsky (1982). Estos patrones generan en los niños, niñas y adolescentes herramientas para lograr construir una forma de ver el mundo a través de su escenario, de la realidad que el contexto escolar genera en la enseñanza aprendizaje, de los esquemas cognitivos que la familia legitima y valida en su forma de organización Minuchin (1984) y en el espacio social desde la retroalimentación y el intercambio que se mimetiza de forma permanente. Mantilla (2005).

\subsection{Políticas públicas de educación especial una mirada a la apuesta en educación}

Durante la década de los años noventa, se dio un impulso al proceso desarrollado en el campo de la educación especial. Frente a este aspecto se observaron incrementos en el presupuesto para la implementación de estos programas a nivel nacional en el ámbito regional, y departamental, contextos en los cuales para ese entonces no existían programas y rubros designados a este tipo de programas; desde esta perspectiva se buscan apoyos que velen por el mejoramiento del proyecto de educación especial, en vía y concordancia con la política de integración educativa direccionadas de la misma forma hacia el nivel Municipal de las llamadas Unidades de Atención Integral al Excepcional (UAEI).

Hacia el año 1968, en el ámbito de Colombia se dan las primeras organizaciones de tipo estructural administrativo, con el fin de dar inicio a los procesos de operativización del programa de Educación Especial, iniciando con la modalidad educativa orientada a la atención de niños, 
INFLUENCIA DOCENTE EN EDUCACION ESPECIAL Y DESARROLLO INTEGRAL 28

niñas y jóvenes con necesidades especiales de visión; este programa es aún conocido como el INCI (Instituto Nacional para Ciegos), el cual inicia con la organización de estos programas, atendiendo de forma integral a niños, niñas y jóvenes ciegos desde Preescolar, Básica Primaria y Secundaria hasta la Universidad.

Por otro lado, y acompañado de este primer programa, se continúa con el programa INSOR (Instituto Nacional para Sordos) el cual aun siendo para población especial, inicia con menor impacto la integración en niveles de Básica Primaria y en mínimo grado la Básica Secundaria.

De igual manera, a pesar que estos programas inician en la zona central de Colombia, se empiezan a implementar en otras regiones del País, de acuerdo a las directrices del Ministerio de Educación. Programas que para ese entonces se identifican como los primeros UAEI, contando con la colaboración del Gobierno Italiano donde se desarrolla una experiencia de integración en una zona sub-urbana del sur occidente de Bogotá.

Así mismo, con los diferentes programas de Integración Educativa se organizan bases para hablar de la escuela abierta que no discrimine y que reconozca las diferencias de sus estudiantes; frente a este aspecto estos programas plantean la necesidad de contar con el apoyo de pedagogos y terapeutas entre otros profesionales que garanticen la plena participación de los estudiantes y el aprovechamiento de sus potencialidades y capacidades.

Es así como al hablar de los programas de la educación especial, los temas de inclusión y las diferentes líneas de acción para mejorar las condiciones políticas, educativas y de derechos, -para el caso de Bogotá (Colombia)- se comenzó el trabajo a nivel escolar en la modalidad de inclusión de aquellos niños, niñas y adolescentes en condiciones diferentes ya fuera a nivel cognitivo o físico. Alcaldía Mayor de Bogotá (2004). 


\section{INFLUENCIA DOCENTE EN EDUCACION ESPECIAL Y DESARROLLO INTEGRAL 29}

A partir de las diferentes experiencias en las aulas se empezó a desarrollar el trabajo con aulas exclusivas, las cuales se caracterizan por ser flexibles y con la posibilidad de ser integradas a los proyectos educativos institucionales. El desarrollo y puesta en marcha de las aulas exclusivas han tomado elementos de las teorías humanistas, ecológicas y cognitivas, es decir de la postura constructivista y del aprendizaje significativo entre otros (Alcaldía Mayor de Bogotá, 2004).

“Desde el punto de vista pedagógico, ideológico y conceptual, la modalidad de atención exclusiva ha vivido un proceso de cambio, en el que se pasa de un enfoque clínico que se enmarcaba en la exclusión con base en etiquetas patológicas, a un enfoque educativo donde se rescata la diferencia y la diversidad. Este cambio ideológico y conceptual legitima la existencia y la labor de estas instituciones sobre la base de este nuevo paradigma" (Secretaría de Educación Distrital de Bogotá, 2004, p.19).

\subsection{Habilidades para la vida}

Las habilidades para la vida desde la OMS se encuentran clasificadas en diez categorías pertenecientes a un grupo grueso de habilidades, las cuales se enuncian a continuación: Habilidades sociales, las habilidades cognitivas conformada entre otros aspectos por el pensamiento crítico y por último la habilidades para el control de las emocione. Aunque esta investigación se centra en el rol del docente en el desarrollo del pensamiento crítico en niños, niñas y adolescentes de educación especial, es importante aclarar cómo el pensamiento crítico hace parte de esta gran categoría.

Retomando a Mantilla (2005), desde la mirada de habilidades para la vida es a partir de espacios como la escuela y la familia que se logra en los estudiantes el despliegue y mejoramiento 
de destrezas psicosociales que son necesarias para el fortalecimiento y la construcción de procesos individuales, familiares, sociales, y comunitarios. En este sentido las habilidades para la vida buscan el desarrollo y la promoción del desarrollo humano. Mantilla (2005) señala que las habilidades psicosociales y las habilidades para la vida que los niños y niñas aprenden y desarrollan, les permite construir y expresar de manera integral su personalidad, así como hacer un excelente uso de los recursos internos y externos con los que cuenta en su entorno, fortaleciendo en las personas la capacidad para resolver las diferentes situaciones que se le presentan en el diario vivir, estimulando el desarrollo de valores y cualidades.

La OMS establece las habilidades para la vida desde un enfoque educativo, que al construirse con los contextos sociales y formativos, posibilita la promoción y fortalecimiento de competencias psicosociales para los niños, niñas y adolescentes; estas habilidades les permitirán avanzar en la lectura del contexto social al cual pertenecen, evaluar las acciones de acuerdo a la toma de decisiones y desarrollar estrategias que les permitan desempeñar un rol acorde a las dinámicas sociales y familiares (Organización Panamericana de la Salud, 2001, p. 6).

\subsection{Desarrollo humano integral su relación con las habilidades para la vida}

La Segunda Guerra Mundial, fue el inicio para nuevas miradas alrededor de los diferentes modelos de crecimiento y de desarrollo económico. Con ello se buscaba identificar y reconocer parámetros que permitieran diferenciar y especificar las variables económicas para caracterizar el contexto; en ese momento las miradas hacia las necesidades sociales y humanas fueron desdibujadas del estudio de necesidades planteadas.

Con el paso del tiempo, las miradas estadísticas referenciadas desde los patrones económicos, empezaron a tener una brecha con las vivencias a nivel social, se evidenciaba empeoramiento frente a las condiciones adecuadas de la calidad de vida, por lo que en ese 


\section{INFLUENCIA DOCENTE EN EDUCACION ESPECIAL Y DESARROLLO INTEGRAL 31}

momento se requirió la revisión de los conceptos de crecimiento económico y distribución de la riqueza (Márquez, 2004).

A comienzos de la década de los años 70, en la Universidad Sussex del Reino Unido, se realizó un estudio sobre las formas de combinar crecimiento y distribución social, que arrojó como conclusiones, las siguientes: necesidad en el aumento de la productividad analizando de quienes y para quienes; la redistribución de los medios de producción y los servicios básicos no era suficiente, sino que, a su vez, debía ser incrementada la productividad de la mayoría de los pobres (Márquez, 2004). Por tal razón en oposición a las mediciones puramente cuantitativas del crecimiento y desarrollo, se comienza a reconocer la importancia del papel humano en la reformulación de la esencia del desarrollo humano. A partir de este momento se hizo significativo el término "desarrollo" como un concepto que abarcaba una visión holística, puesto que la nueva referenciación traspasó el sentido económico, para acercarse al social, cultural, familiar, educativo como aspectos relacionados directamente con la satisfacción de las necesidades planteadas por los seres humanos siendo éstos el objetivo principal del desarrollo.

Esta nueva mirada del desarrollo captó nuevas categorías en la construcción de contextos tanto economicistas como sociales, permitiendo al mundo del desarrollo, hablar no solamente de aspectos frente al consumismo y la distribución económica, permitiéndose así un análisis desde la esfera de la equidad económica y social; es desde este punto que se comienza a plantear una línea del desarrollo a partir de los factores sociales.

El Programa de las Naciones Unidas para el Desarrollo (PNUD) define en su informe de 1995 el desarrollo humano como la intensificación de las oportunidades que puede tener el ser humano; de acuerdo a esta mirada, se encuentra que el desarrollo humano integral cuenta con tres elementos esenciales, a saber: la igualdad de oportunidades para todas las personas en la sociedad, la sostenibilidad de las oportunidades de generación en generación y por último la 


\section{INFLUENCIA DOCENTE EN EDUCACION ESPECIAL Y DESARROLLO INTEGRAL 32}

potenciación de las personas, de modo que participen en el proceso de desarrollo y se beneficien con él (PNUD, 1995, p. 12). Pero porqué hablar desde el desarrollo humano, frente a las habilidades para la vida, es importante rescatar la calidad frente a las posibilidades que tienen las personas para aumentar las oportunidades, de acuerdo al enfoque de las capacidades como un ejercicio para actuar o existir, como elementos que se encuentran implícitos en los procesos de educación (Sen, 2000); de acuerdo a esta mirada en el caso de la personas que presentan déficit cognitivo, se permite plantear la posibilidad de explorar y que estos actores reconozcan por un lado su rol en el contexto social y por el otro la posibilidad de enseñarles a revisar las posibilidades que como seres sociales pueden optar en el espacio que viven y construyen, en palabras de Sen, las libertades reales.

\subsection{Pensamiento crítico y las habilidades para la vida}

El pensamiento crítico hace parte de uno de los conceptos planteados en las habilidades para vida; así mismo, de la organización de los procesos psicológicos superiores, permitiéndole a las personas construir un lenguaje argumentativo frente a las diferentes situaciones cotidianas, llevando a la construcción de fundamentos dinámicos propositivos a nivel del lenguaje, las actuaciones y pensamiento el mismo (García y Bradasic, 2009).

El pensamiento crítico contribuye a la salud y al desarrollo personal y social, al ayudarnos a reconocer y evaluar los factores que influyen en nuestras actitudes y comportamientos y los de los demás; la violencia; la injusticia y la falta de equidad social. La persona crítica hace preguntas y no acepta las cosas en forma crédula sin un análisis cuidadoso en términos de evidencia, razones y suposiciones. El niño o el adolescente crítico aprende a hacer una lectura más personal y objetiva de la publicidad y la enorme avalancha de información transmitida a través de los medios masivos de comunicación (Mantilla, 2001). 


\section{INFLUENCIA DOCENTE EN EDUCACION ESPECIAL Y DESARROLLO INTEGRAL 33}

La finalidad del pensamiento crítico es reconocer aquello que es justo y aquello que es verdadero. Es, en resumidas cuentas, el pensamiento de un ser humano racional. Ennis (1985), citado por Díaz y Montenegro (2010, p.4), refiere el pensamiento crítico como una corriente abstraída, que analiza lo bien fundado de los resultados de su propia reflexión como los de la reflexión ajena.

Para Facione (2007), el pensamiento crítico permite al ser humano abordar las situaciones que se presentan en el diario vivir, teniendo en cuenta el contexto en el cual se presentan y las diferentes alternativas que se pueden construir para la solución de la situación; “el pensamiento crítico es un pensamiento que tiene como propósito probar un punto; interpretar lo que algo significa; resolver un problema, pero el pensamiento crítico puede ser una tarea colaborativa, no competitiva" (Facione, 2007, p.7). En el desarrollo del pensamiento crítico se encuentran presentes habilidades y actitudes, las cuales se conocen como habilidades cognitivas y disposiciones.

Es así como el desarrollo de las habilidades cognitivas, como esencia del pensamiento crítico, se identifican componentes como la interpretación, el análisis, la evaluación, la inferencia, la explicación y la autorregulación. En el año 1992 Facione, realizó un documento donde registró las acciones adelantadas del consenso de expertos. Frente a la definición del pensamiento crítico salieron algunas definiciones para los componentes del mismo, las cuales permiten reconocer más a fondo el sentido de las habilidades que componen este tipo de pensamiento. ${ }^{1}$

\footnotetext{
1 "Los resultados del consenso de expertos citados o reportados en el ensayo desarrollado por Facione Peter, están publicados en la obra Critical Thinking: A Statement of Expert Consensus for Purposes of Educational Assessment and Instruction (Pensamiento Crítico: Una declaración de consenso de expertos con fines de evaluación e instrucción educativa). Peter A. Facione, investigador principal, The California Academic Press, Millbrae CA, 1990. (ERIC ED 315423 ) http://www.insightassessment.com/articles.html.”
} 


\section{INFLUENCIA DOCENTE EN EDUCACION ESPECIAL Y DESARROLLO INTEGRAL 34}

Relacionando el pensamiento crítico con las habilidades para la vida, es importante destacar que estas habilidades a partir del desarrollo de este tipo de pensamiento se verán permeada por actitudes que algunos teóricos han venido clasificando dentro de la categoría de procesos cognitivos (Facione, 2007). La interpretación, como un elemento de comprensión, expresión y significado permite a los sujetos empezar a construir criterios y procedimientos de acuerdo a las reglas que le rodean en los diferentes espacios; por otro lado este autor refiere que la interpretación debe ir perfectamente correlacionada con otras categorías como el análisis, determinado como la capacidad para identificar las diferentes representaciones, para analizar y finalmente consolidar un juicio u opinión.

\subsubsection{El contexto de la familia como un modelo en el desarrollo de las habilidades para la vida}

Ahora bien, de acuerdo a los componentes que hacen parte del desarrollo de habilidades para la vida se encuentra la familia como uno de los contextos que, de alguna manera, permea esta categoría, y así mismo de las diferentes categorías de las habilidades para la vida. Teniendo en cuenta esta investigación, es importante que, de alguna manera, se tenga una mirada de la construcción de familia. Una de las definiciones de familia se encuentra basada en los vínculos de parentesco tal como se conoce hoy, pero tenía antiguamente matices distintos.

De tal manera lo plantea Pachón (2007). Se retoma a la familia como uno de los grupos sociales que hacen parte del contexto sociocultural y para ello es importante tener en cuenta las diferentes clasificaciones que se pueden encontrar sobre los niveles de la actividad cultura, expresados de la siguiente forma: alta cultura, la cual se caracteriza por su carácter distinguido, fundamentándose en la tradición clásica. En esta definición se pueden encontrar algunas formas 


\section{INFLUENCIA DOCENTE EN EDUCACION ESPECIAL Y DESARROLLO INTEGRAL 35}

de organización familiar, siendo objeto de un consumo privilegiado o por sectores altos, distinguiéndose por la presencia de actores profesionales, artistas e intelectuales.

Ahora bien, de acuerdo a la definición de familia y las habilidades para la vida, es importante, rescatar que aunque no es objeto de esta investigación, se requiere reconocer la relación de lo cultural y lo social como elementos predeterminante para las acciones y posturas de los sujetos en un determinado contexto, por esa razón la familia llega a cumplir un papel determinante en este proceso, recordando que el primer núcleo o escenario de socialización del cual hace parte el sujeto y en este caso el niño, siendo el núcleo primario que le enseña al niño o niña reconocer el contexto donde se encuentran las emociones y motivaciones, el proyecto de vida, el rol, las posturas políticas, la mirada religiosa y en mayor medida la construcción de un ser social.

Como refiere (Minuchin, 1984), una familia no sólo tiene estructura, sino un conjunto de esquemas cognitivos que legitiman o validan la organización familiar. La estructura y la estructura creída se apoyan y se justifican entre sí; cualquiera de ellas puede ser una vía de acceso, la familia como grupo central de un contexto social permite con y desde sus integrantes el fortalecimiento de nuevas estructuras sociales, culturales, académicas, vinculares, cognitivas y afectivas (Minuchin, 1984, p.207).

Las familias cumplen el papel de la transformación social integral en la cultura como parte de una herencia social, humana, transmitiéndola en cada uno de los participantes del núcleo familiar; “(...) el hombre nace filogenéticamente como un animal biológico. Será en la convivencia, la interacción primero en la familia y después en la iglesia, clubes etc., donde este “animal social” se convertirá en un semejante muy próximo a nosotros: en un ser humano.” (Ruíz, 2006, p.14). 


\section{INFLUENCIA DOCENTE EN EDUCACION ESPECIAL Y DESARROLLO INTEGRAL 36}

En las diferentes organizaciones sociales que el ser humano ha realizado a lo largo del tiempo, la familia ha sido una de las organizaciones de producción simbólica, desarrollada desde una mirada totalmente humana. Dicha organización tiene como un factor de humanización transmitir su propia estructura con el paso del tiempo; lo que es claro es que la familia pasó a ser algo más que un grupo de encuentro y desencuentro, como un espacio de construcción, acuerdos, aprendizajes, enseñanzas, etc. Desde esta misma línea Berenstein (1992) nos plantea que el ser humano es algo más que el funcionamiento armónico de sus órganos y la familia algo más que una reunión de personas que conviven durante un tiempo prolongado en un lugar determinado.

\subsubsection{El contexto de la escuela y su rol en el desarrollo humano integral}

En el desarrollo de las diferentes investigaciones sobre el aprendizaje de los seres humanos, el contexto escolar ha adquirido un papel protagónico en la explicación de los diferentes espacios de desarrollo; se encuentra que el enfoque cultural se origina y vincula con el contexto educativo, pues este último permite la construcción de formas de pensamiento abstracto, por medio de la utilización del lenguaje, como una de las herramientas mediadora de los cambios en los procesos cognitivos (Martínez, 1999, p.16).

En relación con el objetivo de esta investigación es importante reconocer el papel de la escuela como un contexto sociocultural, que permite en el niño y la niña el desarrollo de habilidades para la vida, no solamente enmarcadas en lo cognitivo, sino a la vez en lo afectivo, emocional y social; llevando con estos elementos al desarrollo del pensamiento crítico desde el entorno educativo.

Retomando a Vygotsky (1982), desde el enfoque sociocultural, se plantea que el niño desarrolla su aprendizaje desde un desarrollo real y un desarrollo potencial acorde al niño. A estos elementos Vygotsky los categorizó como zonas de desarrollo próximo (ZDP). Es 
importante retomar este aspecto ya que tanto para la educación como para el desarrollo de habilidades para la vida al ser humano le está permitido el avance en sus habilidades y la adquisición de nuevos conocimientos. Teniendo en cuenta lo anterior, desde la mirada sociocultural el niño requiere un intercambio de la construcción de su lenguaje y pensamiento. Para este autor la representación egocéntrica del pensamiento se expresa en el lenguaje; de acuerdo a este punto el lenguaje permite la transformación del pensamiento, "la psiquis del hombre es social" Vygotsky (1982). Es importante retomar el papel de la escuela, como lo refiere Viché (2007), teniendo en cuenta el contexto escolar, pues es un sistema que integra el aspecto social, de culturización y desarrollo armónico de todos los aspectos individuales y las experiencias colectivas. Es ahí donde la escuela se convierte en el segundo espacio de socialización de los niños después de la familia. En este orden de ideas la escuela se convierte en uno de los contextos significativos que permiten el desarrollo de habilidades sociales, habilidades para la vida y habilidades cognitivas. 
INFLUENCIA DOCENTE EN EDUCACION ESPECIAL Y DESARROLLO INTEGRAL 38

\section{CAPÍTULO. HABILIDADES PARA LA VIDA. EL DESARROLLO DEL PENSAMIENTO CRÍTICO COMO UN FACTOR HUMANO INTEGRAL EN LA POBLACIÓN DE EDUCACIÓN ESPECIAL. DESAFÍOS O TRIVIALIDADES DEL CONTEXTO ESCOLAR.}

\subsection{La importancia de hablar de desarrollo del pensamiento crítico y los currículos ocultos en el contexto escolar}

De acuerdo a la revisión teórica e investigativa, es importante tener en cuenta que para este trabajo el desarrollo del pensamiento crítico, es tomado como un aspecto facilitador desde el marco de las habilidades para la vida en niños, niñas y adolescentes con déficit cognitivo, que les permita construir una mirada frente a su contexto diario, así como la decisión de unos criterios de autocorrección y sensibilidad al contexto que les rodea, identificándolos como actores primarios partícipes de la construcción de miradas hacia el nuevo contexto social, como sujetos activos, pensantes, constructores de conocimiento enriquecido de preguntas, anécdotas y narrativas vivas y permanentes, independientemente de pertenecer a una población con necesidades educativas especiales.

Frente a la definición del desarrollo del pensamiento crítico se encuentran escritos que, permiten hacer una lectura del desarrollo de esta habilidad en personas que tienen la capacidad de analizar, inferir, comparar, sintetizar entre otros aspectos. Es decir, se realiza un planteamiento desde una normalidad cognitiva. Para Romano (1995) citado, por Boisvert (2004) el pensamiento crítico lo plantea particularmente como el elemento fundamental para la construcción de estrategias de pensamiento. Según el autor, las estrategias de pensamiento representan la secuencia de procedimientos que se efectúan en una secuencia coordinada, desde una resolución de un problema, la toma de decisión, el pensamiento crítico y la formación del concepto. 


\section{INFLUENCIA DOCENTE EN EDUCACION ESPECIAL Y DESARROLLO INTEGRAL 39}

Para Kurffis (1998) citada, por Boisvert (2004), el pensamiento crítico, es un proceso que tiene como propósito explorar un fenómeno, situación, pregunta o problema con el fin de lograr la elaboración de una hipótesis o la posibilidad de llegar a una conclusión al respecto que brinde la oportunidad de integrar toda la información disponible y lograr justificar la respuesta.

Sin embargo, frente a estas definiciones Lipman (1992) plantea en los años setenta la construcción de un programa de filosofía para niños a partir de la presencia de problemas de enseñanza reflejados en los alumnos de la universidad. Reflexionando sobre este punto llegó al convencimiento de que la educación que se daba a los estudiantes tendía más a enseñarles a memorizar que ayudarles a pensar. De acuerdo a esta perspectiva se plantea la necesidad de si bien los niños, niñas y adolescentes desarrollan procesos cognitivos por debajo de lo esperado para su edad, es importante aclarar que su mirada frente a las vivencias diarias reflejan en ellos preguntas claras a la construcción del pensamiento crítico.

Haciendo referencia al punto anterior, en el segundo semestre del año 2015, la psicóloga ${ }^{2}$ de educación especial, realiza trabajo de prevención y promoción frente a temas de sexualidad y proyecto de vida con el grupo de estudiantes del grado séptimo de educación especial quienes se encuentran en el rango de edad de 14 a 15 años y a nivel cognitivo se enmarcan entre déficit cognitivo leve y moderado. Frente al tema, las adolescentes refieren: "Yo no me dejaría embarazar para eso existe el condón”, "No quiero tener todavía hijos", "Yo ya estoy planificando, mi mamá ya me llevó al médico y tengo una cosa en el brazo, para no quedar embarazada”. Los adolescentes refieren "Yo tengo novia, pero nos vemos por Facebook", "mi papá y mi mamá me dicen que primero debo estudiar", "yo por eso tengo amigas". Frente a este aspecto, la docente

\footnotetext{
${ }^{2}$ La psicóloga de Educación especial, actualmente es quien realiza el ejercicio de investigación del tema sobre el cual se circunscribe este documento, lleva en este espacio laborando un año.
} 


\section{INFLUENCIA DOCENTE EN EDUCACION ESPECIAL Y DESARROLLO INTEGRAL 40}

titular del curso en pocas ocasiones realiza retroalimentación o preguntas a las y los estudiantes; se acogen pocas de las palabras utilizadas por los estudiantes con el fin de indagar qué opinan al respecto los estudiantes. Frente a este punto, Lipman (1992) plantea la necesidad de indagar con el estudiante las situaciones de la vida cotidiana con el fin de lograr incentivar en ellos las preguntas problematizadoras que llevan al desarrollo del pensamiento crítico.

De acuerdo a lo anterior, aunque hablar del desarrollo del pensamiento crítico se enmarca en unos pasos y procesos para una cognición "normal", en el diario vivir del contexto escolar de las aulas exclusivas o de educación especial se encuentran claros ejemplos de pautas para el desarrollo del pensamiento crítico y su relación con los currículos ocultos planteados por Casarini (1997). Estos ejemplos son vivencias inherentes que hacen parte del contexto escolar en lo cotidiano, la implementación del currículo formal y su relación con el real; en otras palabras, son estos currículos ocultos, los que en muchas ocasiones pasan desapercibidos, pero en esencia son los que de alguna manera permiten el desarrollo de un pensamiento crítico en los diferentes espacio sociales del cual hace parte el niño, niña o adolescente.

Por otro lado, Torres (1996), refiere la importancia de analizar el sistema educativo y los procesos de enseñanza-aprendizaje que los estudiantes vivencian en su paso por el contexto escolar; desde allí este autor propone no solamente la revisión al currículo evidente en este espacio sino también al currículo oculto el cual Torres (1996) define como "todos aquellos conocimientos, destrezas, actitudes y valores que se adquieren mediante la participación en procesos de enseñanza aprendizaje y en todas las interacciones que suceden día a día en las aulas y que nunca llegan a explicitarse como metas educativas a lograr de manera intencional en el currículum oficial”. Desde allí se puede observar con mayor claridad las situaciones reales de la escuela, facilitándose la reinterpretación desde la investigación para contribuir en el desarrollo 
INFLUENCIA DOCENTE EN EDUCACION ESPECIAL Y DESARROLLO INTEGRAL 41

de prácticas educativas direccionadas a mejorar las condiciones de enseñanza aprendizaje de los estudiantes.

\subsection{El desarrollo del pensamiento crítico como una habilidad para la vida en niños, niñas y adolescentes con necesidades educativas especiales}

La definición del pensamiento crítico y su importancia como una habilidad para la vida, es fundamental ya que este tipo de pensamiento se plantea como el juicio autorregulado y con propósito que da como resultado la interpretación, el análisis, la evaluación y la inferencia; asimismo, resulta en la explicación de las consideraciones de evidencia conceptuales, metodológicas, contextuales en las cuales se basa ese juicio (Illescas, J, 2011, p.11); es así como este pensamiento regula las formas en que los sujetos plantean los diferentes rumbos que se pueden tomar frente a las diferentes situaciones, así el niño o niña, empieza a auto rectificar las miradas, la decisiones, los juegos, etc.

El pensamiento crítico "es un pensamiento capaz y responsable en tanto que conduce al juicio porque se apoya en los criterios, es autocorrectivo y sensible al contexto" (Lipman, 173, enunciado por Illescas, 2011).

\section{Diario de Campo:}

El día 14 de Abril de 2015, un estudiante del curso $402^{3}$, de once (11) años, diagnosticado con déficit cognitivo limítrofe, a quien en algunas ocasiones se le encontraron objetos que no

\footnotetext{
${ }^{3}$ El estudiante es un preadolescente de once años que lleva asistiendo al aula exclusiva o de educación especial desde hace aproximadamente dos años; durante este tiempo ha presentado historial de hurto y desacato a la norma. Su familia se encuentra conformada por su progenitora y un hermano. Cuando se hace referencia a coeficiente intelectual limítrofe, son aquellos niños, niñas o adolescentes en quien prima la dificultad para lograr los aprendizajes esperados para su edad y que puede presentar problemas a nivel emocional entre otros aspectos. DSM IV.
} 
eran suyos, se le encontraron seis refrigerios en la maleta; frente a esta situación la terapeuta ocupacional (T.O), llamó a la psicóloga de educación especial, refiriéndole que el adolescente se había robado esos refrigerios, ante la situación la T.O, le llamó la atención al adolescente, frente a esta aspecto el estudiante refería que él no se los había robado y que una docente del aula regular se los había dado, la psicóloga realiza el debido proceso, primero escuchar al estudiante, quien en su estructura de pensamiento era coherente y a nivel emocional estaba tranquilo, en compañía de la profesional se hizo la búsqueda respectiva de la docente, con quien final se constató que el estudiante tenía la razón.

\section{Figura 1}

Un espacio para reconocer el contexto.

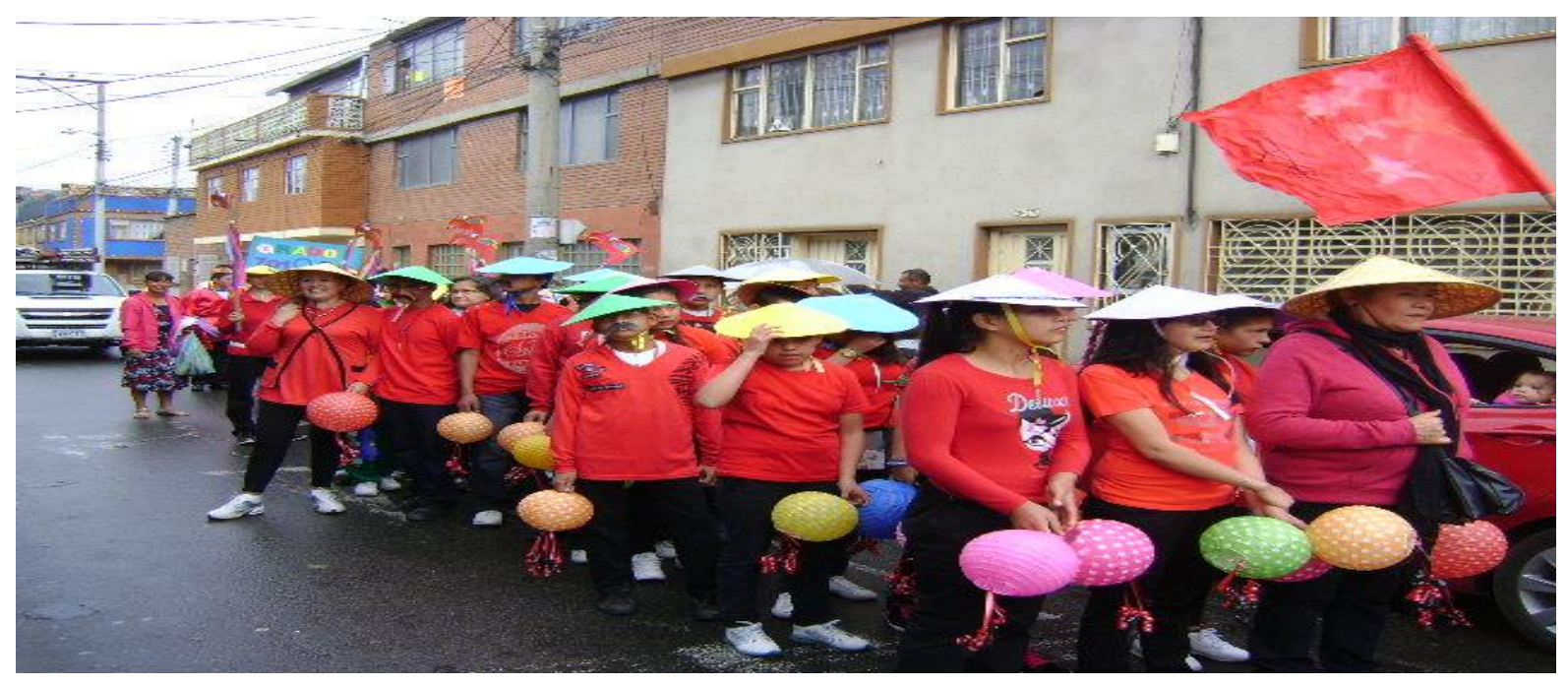

Fuente: Inauguración juegos deportivos Colegio Gustavo Restrepo Sede C jornada mañana 2015.

La escuela es un escenario que permite a los niños y niñas abstraer de forma permanente los conocimientos adquiridos en el aula de clase; sin embargo, es importante aclarar que el rol del maestro en el aula de clase es permitir al estudiante la construcción de un conocimiento consciente, real; aterrizar la teoría a la realidad y la realidad a la teoría, o como lo plantea Mertes (Mertes, p, 24 enunciado por Illescas, 2011 ), “es un proceso consciente y deliberado que se 


\section{INFLUENCIA DOCENTE EN EDUCACION ESPECIAL Y DESARROLLO INTEGRAL 43}

utiliza para interpretar o evaluar información y experiencias con un conjunto de actitudes y habilidades que guíen las creencias fundamentales y las acciones".

En el marco de lo anterior se lograría generar desde el pensamiento crítico el desarrollo de habilidades en niños y niñas, que les permita conceptuar, analizar, sintetizar y evaluar la información a partir de la experiencia, el intercambio de experiencias con la familia, el contexto educativo, los pares para finalmente construir un camino direccionado a la transformación del cual son parte. Como lo plantea Carrillo (2009), el contexto escolar es un coctel de sentimientos, intereses y conflictos que se generan a partir de las prácticas sociales que en este espacio también se circunscriben y que permiten la transformación de formas de pensar, sentir y construir conocimiento.

Retomando a Ennis (Ennis,1.989, enunciado por Illescas J, 2011) es rescatar, desde el pensamiento crítico la posibilidad de una mirada evaluativa, que permita fortalecer la toma de decisiones frente al qué creer o hacer. Esto implica un juicio de valor de las acciones y situaciones que se presentan en los diferentes contextos de los cuales son partícipes niños y niñas teniendo en cuenta que a partir de la construcción del pensamiento crítico se puede fortalecer la resolución de problemas, una mirada de acción a los mismos con la posibilidad de adquirir una posición frente a la situación evidenciada, la definición del pensamiento crítico se encuentra elaborada desde diversas miradas y posturas, donde el pensamiento se encuentra enmarcado desde una habilidad cognitiva para la vida, el cual le permite al individuo tomar decisiones frente al que hacer o creer.

De otra parte, el uso permanente de criterios que se proponen, se aplican y se evalúan de forma constante, hacen que sea una forma de pensamiento esencialmente auto correctiva, que en 


\section{INFLUENCIA DOCENTE EN EDUCACION ESPECIAL Y DESARROLLO INTEGRAL 44}

vez de guiarse por principios absolutos, examina en cada caso las circunstancias que determinan un contexto (Illescas, 2011).

\subsection{Niños, niñas y adolescentes de educación especial}

Teniendo en cuenta las particularidades que se evidencian en los colegios distritales frente a los procesos pedagógicos de los estudiantes y basados en declaración universal de los derechos humanos (Art. 19) frente a las medidas apropiadas para la rehabilitación de las personas mental o físicamente impedidas, así como la declaración de los derechos del retraso mental, la constitución política de Colombia y el decreto 2082 del 18 de Noviembre de 1996 del Ministerio

de Educación Nacional, se continúa en la implementación de programas para niños, niñas y adolescentes que presentan déficit cognitivo caracterizado (Secretaría de Educación Distrital 2004).

\subsection{Una mirada al pensamiento crítico reflexivo, desde el contexto de la escuela}

Existen diversos autores que abordan el tema del pensamiento crítico definiendo y estableciendo la importancia de éste para el desarrollo de habilidades como el ánimo de indagación y la postura frente a diversos acontecimientos, entre otros aspectos.

En este acercamiento, Vásquez (2010) plantea que la escuela tiene un papel fundamental en la construcción del pensamiento crítico en tanto es ésta un escenario fundamental en la construcción del conocimiento, el pensamiento, la mirada ante la vida y la proyección social; aborda el rol que cumple el contexto educativo y desarrolla temas como el pensamiento y la actuación problematizadora en la enseñanza, la educación y la teoría crítica y, por último, la educación y el actuar comunicativo.

Sobre el sentido que tiene la pedagogía en la construcción del pensamiento crítico, demarca el planteamiento crítico reflexivo como una habilidad que se cultiva en el sistema 


\section{INFLUENCIA DOCENTE EN EDUCACION ESPECIAL Y DESARROLLO INTEGRAL 45}

escolar al tener en cuenta que el maestro, el estudiante, el niño y el joven se han de reconocer y consolidar como sujetos históricos, a la vez que como sujetos de deseo, susceptibles de historicidad y de proyección onírica, constituidos por facultades crítico-creativas que surgen del asombro; es decir, el pensamiento crítico reflexivo le permite al niño y la niña la construcción de espacios, constituyendo su diario vivir, en escenarios reales, permanentes y constructivistas. El autor elabora este planteamiento a partir de filósofos como Nietzsche y algunos teóricos de la Escuela de Fráncfort, entre otros (Vásquez, 2010).

Como una forma de reconocer la importancia del espacio educativo en el desarrollo del pensamiento crítico desde una estrategia que favorece las habilidades para la vida, configurándose una herramienta que permite a los niños y niñas integrar y desarrollar en su diario vivir, elementos para resolver problemas y pensar, (Gómez y Salamanca, 2008), desde esta investigación de corte cualitativo, a través de la investigación acción educativa, se argumenta la importancia de desarrollar un pensamiento crítico en los niños y niñas, encaminado a la argumentación, explicación y sustentación de soluciones, miradas y acciones, involucrando la mirada de docentes, administrativos y estudiante, llevando al fortalecimiento de habilidades para la vida desde la consolidación del pensamiento crítico.

Retomando el ejercicio del desarrollo del pensamiento crítico desde una habilidad para le vida es importante retomar situaciones que en el contexto diario de la escuela se presentan.

\section{Diario de Campo:}

El día 19 de Agosto de 2015 se llama la atención por agresión a un estudiante de once (11) años, con un déficit cognitivo moderado perteneciente al curso $401^{4}$, quien durante el tiempo

\footnotetext{
${ }^{4}$ Estudiante de 11 años, quien asiste a las aulas diferenciales desde enero de 2015, de acuerdo a la evaluación psicológica presenta un retardo mental moderado, es decir que para la edad cronológica su edad mental corresponde a la de un niño de aproximadamente cuatro años ochos meses, al ingreso escolar este estudiante se
} 


\section{INFLUENCIA DOCENTE EN EDUCACION ESPECIAL Y DESARROLLO INTEGRAL 46}

escolar ha tenido llamados de atención por parte de la docente titular, la trabajadora social y otras docentes, por presentar la misma situación; se le planteó que no debía golpear a otros niños; frente a este llamado de atención el estudiante refirió los siguiente, "por qué no le puedo pegar si él también me pegó y siempre me molesta, yo no voy a dejar que me pegue más”. Es así como el contexto escolar permite generar escenarios de reflexión evidentes también en la población de educación especial.

Aunado a esta mirada, en las investigaciones realizadas en Colombia se encontró la aplicación del modelo constructivista socio-crítico en la Escuela Normal Superior de Acacias Meta (ENSA) el cual, en la actualidad, es el instrumento que muestra la realidad pedagógica de la ENSA, orienta todos el proceso educativo y genera una concepción particular de los núcleos del saber pedagógico para que la propuesta de formación integral y del pedagogo infantil acreditada previamente por el Ministerio de Educación Nacional (MEN) se dé en las mejores condiciones. Esto a partir del fundamento desde el enfoque socio-crítico, el cual al partir del fortalecimiento del pensamiento crítico, permite a los niños, niñas, adolescentes y egresados comprender las dinámicas sociales, individuales y familiares desde una mirada holística e integral.

La mirada de habilidades para la vida es una estrategia desarrollada desde la OMS y para el caso de Colombia, se ha venido desarrollando por la institución Fe y Alegría, entidad que tiene como horizonte contribuir a la promoción del desarrollo personal y social, sin olvidar el fortalecimiento de los derechos humanos y la prevención y promoción ante elementos psicosociales y de salud (Mantilla, 1997, p3).

caracterizaba por presentar conductas oposicionistas hacia la norma, agresividad hacia los compañeros y dificultad para relacionarse con las figuras adultas. Se inicia trabajo familiar e individual logrando mejorar en el preadolescente conductas prosociales, de igual forma mejora nivel académico y actitudinal. 
INFLUENCIA DOCENTE EN EDUCACION ESPECIAL Y DESARROLLO INTEGRAL 47

\section{CAPITULO LA INFLUENCIA DEL CONTEXTO ESCOLAR EN EL DESARROLLO DEL PENSAMIENTO CRÍTICO EN NIÑOS, NIÑAS Y ADOLESCENTES DE LAS AULAS EXCLUSIVA}

\subsection{Análisis de la población docente de las aulas exclusivas}

Las aulas exclusivas o aulas de educación especial del Colegio Gustavo Restrepo Sede C, jornada de la mañana, se encuentra conformada por ocho docentes pedagogas versadas en educación especial. En el desarrollo de la investigación, se contó con el apoyo de seis docentes de aula y tres profesionales de apoyo. A continuación, se realiza una breve descripción de cada una de las docentes y del equipo de apoyo.

Cada una de las docentes se encuentra a cargo de un curso, la docente Claudia ${ }^{5}$ se encuentra a cargo del curso 501; actualmente lleva treinta y dos años ejerciendo el cargo de docente en educación especial, su título de pregrado profesional es en área de educación preescolar. Frente a la pregunta sobre la motivación para laborar en el campo de la educación especial, la docente refiere que: "me incliné por el área donde más podría ayudar, veía que los niños que tenían alguna discapacidad eran muy vulnerables al maltrato, a la segregación etc. y mi objetivo siempre ha sido dar la mano a quien lo necesita", de acuerdo a este aspecto y en la labor diaria con la docente, desde el área de psicología, en la cual la me desempeño como docente de apoyo y de acuerdo a Casarini (1997) quien nos plantea la importancia de reconocer los currículos ocultos en los espacios del diario vivir, la docente siempre esboza en sus clases y los espacios que comporte con los estudiantes la necesidad, de reconocer la realidad social en la cual se vive, de tal forma que en los procesos de retroalimentación permite a sus estudiosos responderse preguntas que los llevan a generar respuestas y preguntas en un contexto real.

\footnotetext{
${ }^{5}$ Con el fin de mantener en reserva los nombres relacionados con las respuestas brindadas durante el proceso de las entrevistas, se realiza cambio en nueve de los nombres de las docentes, se conserva el nombre de la psicóloga de las aulas de educación especial jornada mañana, sin embargo las fuentes orales conservan los nombres reales, teniendo en cuenta que hay carta de consentimiento.
} 


\section{INFLUENCIA DOCENTE EN EDUCACION ESPECIAL Y DESARROLLO INTEGRAL 48}

La docente Gloria, se encuentra a cargo del curso 601, actualmente lleva treinta y un años, ejerciendo este cargo; sobre la afinidad para laborar en el campo de la educación especial, la docente refiere "mi objetivo era diferente al que actualmente desarrollo. Tenía dos opciones para estudiar, psicopedagogía y educación especial, por suerte estudié educación especial.”, en este punto y retomando las agendas ocultas que se plantean desde el área de psicología, la cuales se conocen en educación como currículos ocultos, durante el proceso de investigación y de entrevistas con la docente, en el aspecto motivacional, la docente Gloria, recuerda que el motivo para ser docente, no fue el gusto por el área, sino una decisión de sus padres quienes, no le permitieron estudiar secretariado; en este aspecto durante el intercambio de experiencias pedagógicas en el espacio laboral con la docente, se encontró espacios de intercambio donde expresa aunque su gusto por el secretario continua vigente. La docente Gloria es especialista en recreación ecológica.

La docente Susana lleva ejerciendo treinta años en el cargo de docente de educación especial, actualmente se encuentra a cargo del curso 301, la docente refiere que lo que la motivo a trabajar en esta área era: "ayudar y sacar los niños adelante y que pudieran defenderse en la vida, ser independientes en la medida de sus posibilidades y el obtener algunos logros”.

\section{Figura 2}

Tiempo laborando como docente en educación especial o aulas exclusivas. 


\section{TIEMPO DE LABOR DOCENTE EN EDUCACIÓN ESPECIAL MEDIDO EN AÑOS}

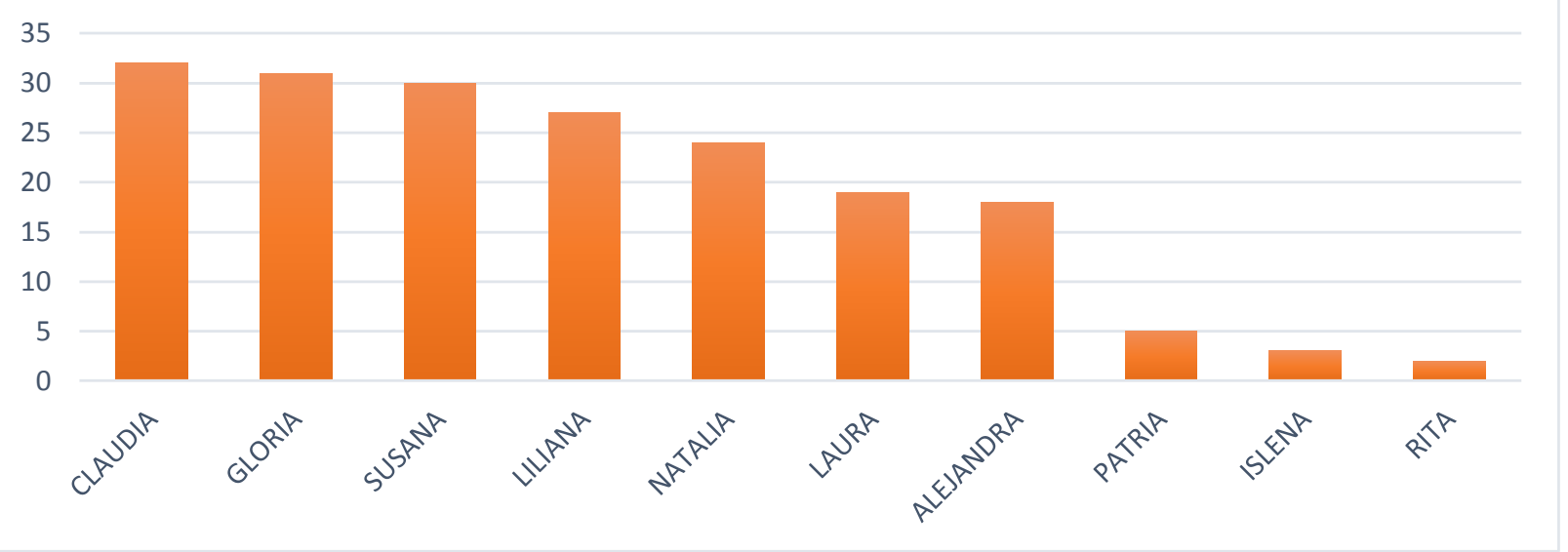

Fuente: Elaboración propia, a partir del instrumento de caracterización desarrollado en el proceso de investigación. Este instrumento se planteó teniendo que una de las categorías de análisis era la influencia docente. Para ello se consideró significativo identificar el tiempo de labor y la dirección directa tanto con los procesos pedagógicos, como del rol en la educación de los niños, niñas y adoles2centes de educación especial aulas exclusivas.

La docente Liliana lleva ejerciendo veintisiete años como educadora especial, actualmente se encuentra a cargo del curso 401; la docente refiere ante la labor con niños, niñas y adolescente de educación especial lo siguiente: “el trabajo con estos niños es muy emotivo, aunque los logros son muy pocos y muy lentos con algunos, su trato y relación son muy satisfactorios por su acercamiento y cariño que ellos tienen". "Soy educadora especial y me gusta trabajar con estos niños", frente a este aspecto en el currículo oculto de la docente de acuerdo a su discurso se direcciona a la cosificación del estudiante al tener en cuenta su expresión "estos niños", como un sujeto que está en el contexto con quien se puede llegar a ciertos puntos de avance, pero que teniendo en cuenta la pregunta de investigación los enmarca como sujetos que asisten al contexto educativo, pero que difícilmente logran los avances esperados, retomando la 


\section{INFLUENCIA DOCENTE EN EDUCACION ESPECIAL Y DESARROLLO INTEGRAL 50}

historia de la educación especial, teniendo en cuenta la revisión bibliográfica, esta forma de respuesta, se encuentra enmarcada desde la labor de la docente en una perspectiva de los años 60 sobre el idiota y su categorización desarrollista .

La docente Natalia lleva trabajando como educadora especial veinticuatro años, se encuentra a cargo del curso 402, es especialista en edumática y pedagogía de la recreación ecológica, frente a su labor como docente refiere "siempre he trabajado en aula exclusiva, prefiero el trabajo en ellos porque me gusta estar con los niños, ellos son mi gran motivación día a día", en el mismo sentido del gusto por la labor docente en educación especial la docente Natalia hace referencia a la importancia de ser recursiva en los procesos pedagógicos con los niños y niñas; en el proceso académico.

Como psicóloga de educación especial en la institución he encontrado en el desempeño de los estudiantes a cargo de la docente Natalia espacios donde son ellos quienes hacen preguntas frente a los acontecimientos de la vida diaria y la posible respuesta a los problemas sencillos que viven ellos de alguna manera como lo refiere la docente " el reto de tratór de sacar adelante a un estudiante es lo que más le agrada de ser docente es esta área", se evidencia en las formas de pregunta de los estudiantes, como solucionan problemas sencillos y el reconocimiento de sí mismo en el espacio escolar y familiar.

La docente Patricia, lleva laborando como educadora especial cinco años, actualmente se encuentra a cargo del curso 201. Frente a la motivación por trabajar con niños, niñas y adolescentes de educación especial refiere "me permite partir de las necesidades de cada niño, es satisfactorio los pequeños logros y el apoyo de las familias", en el intercambio de experiencias con la docente desde el área de psicología la cual encabeza en la sede C jornada mañana, se ha logrado llegar a conocer los procesos académicos que la docente lleva a cabo con los estudiantes que se encuentran a su cargo, en este aspecto la docente está a cargo de 15 niños y niñas que se 


\section{INFLUENCIA DOCENTE EN EDUCACION ESPECIAL Y DESARROLLO INTEGRAL 51}

encuentran en edades de nueve (9) a once (11) años de edad, frente a la este aspecto el material de trabajo lleva a lograr en los estudiantes respuestas de atención y concentración , sin embargo no se logra evidenciar elementos que le permitan a los niños y niñas indagar frente a situaciones sencillas de la vida diaria, como lo plantea Illescas (2001), el desarrollo del pensamiento crítico lleva a plantear en los sujetos los rumbos a tomar frente a las situaciones, es decir el niño auto rectifica la mirada de su entorno.

La trabajadora social (T.S) Laura lleva diecinueve años en el cargo de profesional de apoyo en las aulas exclusivas o aulas de educación especial. Su labor, además de realizar el proceso inicial de ingreso a nuevos estudiantes, es el de velar porque los derechos de los estudiantes de educación especial se están fortaleciendo e incentivando tanto al interior del contexto escolar como de las familias, así como realizar apoyo a las docentes de educación especial; frente a la motivación por ejercer este cargo la T.S, refiere "era docente de primaria: terminé la carrera y tenía la expectativa de ejercer mi profesión”; es especialista en derecho de familia.

La Terapeuta de lenguaje y especialista en pedagogía de la recreación ecológica Alejandra, lleva dieciocho años en este cargo; su labor es fortalecer los aspectos relacionados con los problemas fonológicos y articuladores presente en los niños, niñas y adolescentes de educación especial. Frente a la motivación por trabajar con la población de aulas exclusivas la Terapeuta de Lenguaje refiere que su proceso de labor inicio por la: "presentación a concurso de terapia de lenguaje como docente de apoyo, en terapia del lenguaje, el programa tiene gran necesidad de esta área, siempre se abordan los procesos de detección, diagnóstico, abordaje y prevención". Retomando las agendas ocultas, frente al planteamiento motivacional de la profesional en terapia de lenguaje, ha planteado su interés en hacer parte del programa teniendo 


\section{INFLUENCIA DOCENTE EN EDUCACION ESPECIAL Y DESARROLLO INTEGRAL 52}

en cuenta que por ser docente de planta, "tiene asegurado su ingreso económico, razón por la cual lleva 18 años en el colegio".

La Terapeuta ocupacional Rita, que lleva dos años laborando en el campo de la educación especial, refiere frente a la motivación por laborar con los estudiantes de educación especial que para ella es significativo "poder contribuir al avance de los niños y niñas con discapacidad" de igual manera se encuentra una coherencia entre el aspecto motivacional y el agrado por ser docente de educación especial donde no solamente busca que los estudiantes logren la adquisición de teorías y conceptos pedagógicos, sino como refiere ella "poder hacer un aporte al empoderamiento de las familias y niños y niñas con discapacidad para el ejercicio de sus derechos y la búsqueda de la igualdad”.

Es importante reconocer los intereses de cada una de las personas que se encuentran a cargo de los niños, niñas y adolescentes que hacen para de las aulas exclusivas, con el fin de explorar como estos intereses direccionan los proyectos de vida tanto en las docentes como en los diferentes estudiantes que han hecho, hacen y harán parte del programa de educación especial.

El tiempo de servicio en el cargo influye en el desempeño que realizan con las y los estudiantes. Es interesante encontrar, como lo refiere Torres (1996), que los currículos ocultos hacen parte de la cotidianidad y el intercambio del aprendizaje-enseñanza; se encuentra, que aunque para docentes como Claudia y Natalia, la labor docente hace parte de su interés profesional y personal; para las docentes Gloria y Alejandra, la labor en la cual llevan varios años se genera a partir de una necesidad profesional que lleva a desempeñar su profesión en el campo de la educación especial; como lo refiere Martínez (1999), las prácticas educativas se convierten en elementos que los actores permean de manera constante; cambian, reestructuran y fortalecen a nivel cognitivo y social, como primera medida desde las necesidades individuales e inmediatas y en segunda instancia desde las particularidades del medio. 


\section{INFLUENCIA DOCENTE EN EDUCACION ESPECIAL Y DESARROLLO INTEGRAL 53}

Teniendo en cuenta el planteamiento de Casarini (1997) frente al significado de los currículos ocultos en la construcción del conocimiento de los contextos que hacen parte ,de las aulas de educación especial se encuentra al interior de la dinámica docentes aspectos relacionados con el interés directo a la consecución de un espacio laboral que permita la estabilidad laboral y profesional que en el contexto privado es difícil sostener teniendo en cuenta los parámetros del cumplimiento del horario, los días laborales, el reconocimiento profesional y la estabilidad laboral, frente a este aspecto se encuentran currículos ocultos direccionados a laboral en un espacio pedagógico que permite asegurar el aspecto laboral y económico, dejando a un lado el aspecto personal que en algunas docentes se ve truncado por el aspecto familiar y laboral, estas variables son inherentes al desarrollo laboral y profesional que en algunas docentes lleva a cosificar al estudiante y generar contradicciones en el discurso de los diferentes intercambios de experiencias profesionales; por otro lado teniendo en cuenta a (Torres,1996, p.14) quien plantea la importancia de las instituciones escolares en la construcción social e históricas, frente a la mirada de las docentes Gloria al haber estudiado educación especial, durante un espacio de descanso escolar, ante una pregunta de lógica matemática donde se le dificultó emitir la respuesta, refiere "Después de tanto tiempo de estar en estas aulas, a uno como que algo se le pega y se vuelve lento"; hasta qué punto las docentes en su quehacer como educadoras especiales teniendo en cuenta el tiempo de labor de más de veinte años, llevan a cuestionarse por un lado la labor en el ejercicio enseñanza aprendizaje, los espacios que deben cumplir en tiempo, los cambios frente a la población que actualmente hacen parte de las aulas de educación especial quienes presentan mayores dificultades que los estudiantes de hace unos años atrás, entre otros aspectos; frente a lo anterior en el proceso de la investigación se encontró que la mayoría de las docentes presentan deseperanza aprendida frente a la labor que realizan con los estudiantes de educación especial, de acuerdo a este aspecto cumplen con los horarios establecidos, mantienen 


\section{INFLUENCIA DOCENTE EN EDUCACION ESPECIAL Y DESARROLLO INTEGRAL 54}

a los grupos en el salón de clase, pero no establecen cambios en las acciones pedagógicas que permitan romper con la dinámica actual de los estudiantes de educación especial y la innovación.

\subsection{Población de estudiantes de las aulas exclusivas}

Las aulas exclusivas del colegio Gustavo Restrepo, sede C, jornada mañana, actualmente se encuentran conformadas por un total de ciento veintiocho estudiantes, de edades entre ocho (8) y quince (15) años; cada uno de los curso cuenta con dieciséis estudiantes ubicados en los ciclos de educación I, II y III este tipo de organización administrativa se realiza teniendo en cuenta que el ciclo I está conformado por los cursos de primero (1) y segundo (2) donde de acuerdo a la Secretaria de Educación de Bogotá (2010), es importante trabajar los ejes de estimulación y exploración, el ciclo II son los cursos correspondientes a tercero (3) y cuarto (4), caracterizado por los ejes de desarrollo y experiencia y finalmente el ciclo III conformado por los cursos de quinto (5) sexto (6) y séptimo (7) con la impronta del ciclo a nivel Distrital conocida como la interacción social y construcción de mundos posibles, los ejes de desarrollo de este ciclo se encuentran direccionados hacia la indagación y experimentación.

La organización de cada uno de los cursos las docentes de educación especial la han definido teniendo en cuenta la edad de los estudiantes; de acuerdo a este parámetro se encuentra que el grupo de la docente Patricia, 201 está conformado por estudiantes que tienen entre ocho y once años; el grupo de la docente Susana, 301 se encuentra conformado por niños, niñas, preadolescentes y adolescentes entre los nueve y trece años.

El grupo de la docente Liliana, 401 está conformado por niños, niñas, preadolescentes y adolescentes entre nueve y trece años. Por otro lado, el grupo de la docente Natalia, 402 está conformado por estudiantes entre los diez y once años es decir preadolescente y adolescentes. El grupo de la docente Claudia, 501 está conformado por estudiantes entre los doce y catorce años; 


\section{INFLUENCIA DOCENTE EN EDUCACION ESPECIAL Y DESARROLLO INTEGRAL 55}

y finalmente el grupo de lado a la docente Gloria 601, se encuentra conformado por estudiantes entre los doce y catorce años.

De acuerdo al aspecto anteriormente descrito se evidencia que a nivel cronológico los estudiantes de educación especial en su gran mayoría tienen un desarrollo físico de acuerdo a los parámetros antropométricos de edad y sexo, se plantea que la mayoría y no todos, ya que en el caso de la población de estudiantes de educación especial pertenecientes a la sede C, se encuentran otros diagnósticos asociados al déficit cognitivo, como alteraciones en el crecimiento, los cuales en ocasiones no concuerdan con la mediciones antropométricas.

Por otro lado se encuentra que los cursos organizados desde el área de pedagogía no se designan teniendo en cuenta las habilidades y capacidades de cada uno de los estudiantes independientemente del tipo de déficit cognitivo; teniendo en cuenta este aspecto y retomando a Viché (2007), es importante que las aulas exclusivas o aulas de educación especial, como un contexto complementario al sistema sociocultural, desarrolle una práctica educativa encaminada al énfasis de la educación integral, desarrollando su currículo a partir de las necesidades de los estudiantes, trabajando desde el proceso armónico de las personalidades, capacidades y habilidades individuales.

En el proceso de ubicación por edades de los diferentes salones, es importante rescatar que de acuerdo al tipo de déficit cognitivo que presenta cada uno de los estudiantes y de enfermedades asociadas, estos diagnósticos permiten identificar las necesidades que cada uno de los estudiantes requiere trabajar, con el fin de desarrollar nuevas capacidades y habilidades en ellos; retomando este aspecto con el desarrollo del pensamiento crítico, es claro que de acuerdo a su déficit, cada uno de los niños, niñas y adolescentes tendrán una posición frente a las diferentes situaciones que se le presenten en su cotidianidad, como lo refiere Facione (2007). El 
pensamiento crítico permite al ser humano abordar las situaciones que se presentan en el diario vivir, teniendo en cuenta el contexto en el cual se presentan y las diferentes alternativas que se pueden construir para la solución de la situación.

\section{Figura 3}

Caracterizaciones niñas, niñas y adolescentes de Educación especial Sede C, jornada mañana

\section{TIPO DE DEFICIT PRESENTE EN LAS AULAS EXCLUSIVAS SEDE C JORNADA MAÑANA}
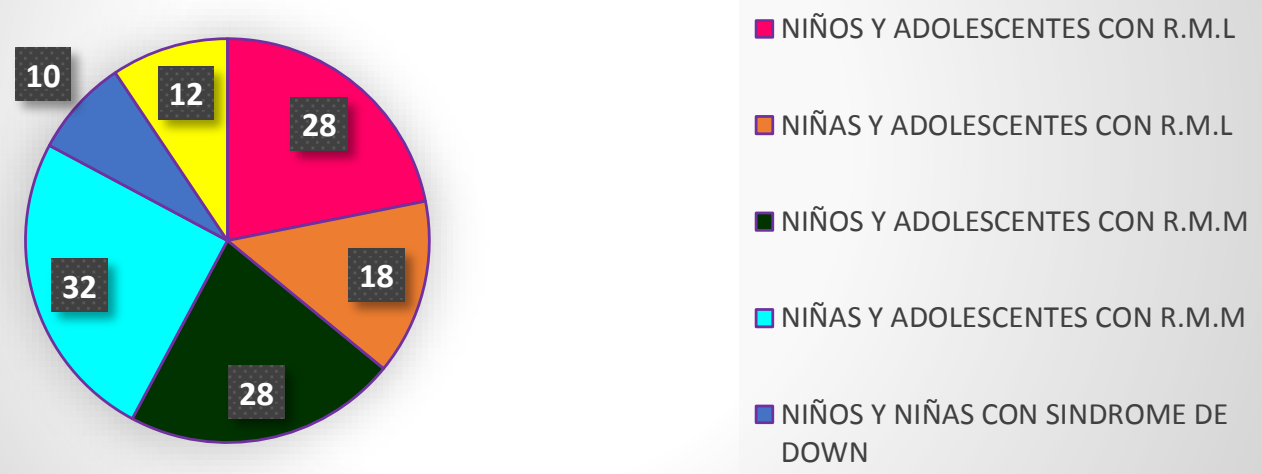

Fuente: Elaboración propia, a partir del instrumento de caracterización desarrollado en el proceso de investigación. Este instrumento se planteó para reconocer la confirmación del grupo de estudiantes de educación especial. El cual se caracteriza por la presencia de un Retardo Mental Leve (R.M.L) o un Retardo Mental Moderado (R.M.M). Cuando se hace referencia a otros factores asociados, se plantean situaciones de problemas de conductas, medicación por psiquiatría o problemas cognitivos heredados de problemáticas médicas.

Es decir, la importancia del docente que pertenece al aula de educación especial cobra aún un mayor significado cuando se rompe con el paradigma del asistencialismo y el fortalecimiento de un currículo establecido y no de un currículo que permita el desarrollo de nuevas perspectivas a nivel socio afectivo y cognitivo, el desarrollo del pensamiento crítico; 
como lo definen Facione (2007) y Lipman (1992) se lleva a cabo a partir del intercambio con el contexto circundante y la exploración de las habilidades y las actitudes ante la situación evidenciada, de acuerdo a este aspecto es importante reconocer en el estudiante las habilidades, capacidades y potencialidades que este llegue a desarrollar y que el contexto escolar en cabeza de las docente coadyuve a desarrollar y fortalecer, se requiere no solamente reconocer el déficit que presenta el estudiante sino el estudiante que puede presentar el déficit, frente a este aspecto y retomando a Facione (2007), Lipman (1992) Sen (2000), se requiere reconocer al sujeto en el contexto social e individual y no solamente al diagnóstico del déficit para permitirle a este ser humano construir su propia historia y experiencia en un mundo de experiencias y conocimiento teórico, cultural, social y político, al niño, niña o adolescente de educación especial se le debe permite conocer, vivir, revivir e identificar el mundo en el que vive el mundo que le permite ser el mundo que le lleva a ser y no desconocer lo que puede ser.

\section{Figura 4}

Localidades de procedencia de los estudiantes de Educación especial

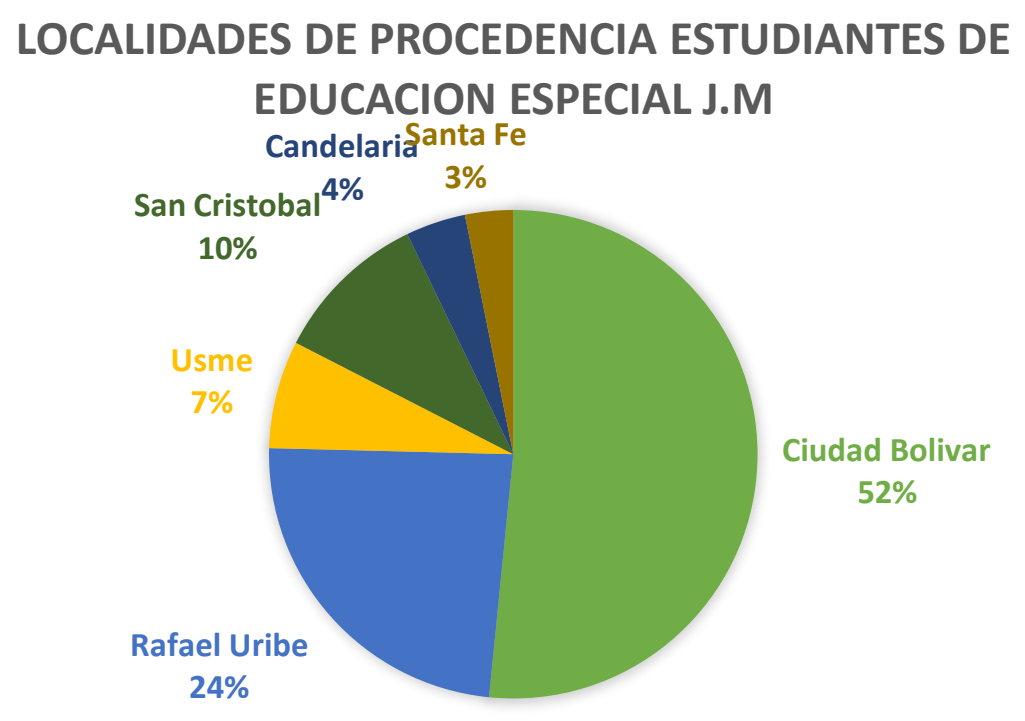




\section{INFLUENCIA DOCENTE EN EDUCACION ESPECIAL Y DESARROLLO INTEGRAL 58}

Fuente: Elaboración propia, a partir del instrumento de caracterización desarrollado en el proceso de investigación, entrevista a la trabajadora social, revisión de datos de registro por rutas escolares año 2015, jornada de la mañana Colegio Gustavo Restrepo sede C, estudiantes de Educación Especial.

De acuerdo al registro realizado desde el área de Trabajo social se encuentra que del totla de estudiantes que hacen parte de las aulas de educación especial en la jornada de la mañana, el cincuenta y dos porciento tienen como procedencia la localidad de Ciudad Bolívar, de acuerdo a este aspecto se encuentra que el Colegio Gustavo Restrepo y específicamente la sede C de educación Especial a novel de la ciudad de Bogotá es reconocida como una institución que encabeza este programa, por otro lado se logra dilucidar que solamente el veinticuatro porciento de los estudiantes hacen parte de la localidad dieciocho de la cual hace parte la institución educativa, desde este análisis es importante preguntarse frente al traslado que sucede con la calidad de vida de los estudiante que deben viajar diriamente en las rutas escolares fuera de sus localidades, se reconoce la dinámica de cada uno de los estudiantes, se identifican las necesidades, que sucede con las familias, entre otros aspectos.

\subsection{La influencia docente en las aulas exclusivas}

Durante el proceso de la investigación, la relación entre tiempo de servicio como docentes en las aulas exclusivas y la profesión, se comprendieron como elementos transversales en la influencia del docente en el desarrollo humano integral, de niños, niñas y adolescentes.

La reciprocidad entre el tiempo de labor en las aulas exclusivas, la formación frente a la especialidad y los diferentes cursos cualificadores de la hoja de vida y las diferentes estrategias de enseñanza con los estudiantes que hacen parte de las aulas, es relevante en relación con la mirada que se tiene en la actualidad de las personas que hacen parte de la educación especial, sin 
embargo en las dinámicas al interior de las aulas de clase de educación especial la cualificación se fragmenta en el proceso de enseña que se imparte actualmente, hago referencia a este aspecto teniendo en cuenta que de acuerdo a las teorías trabajadas por Lipman (1992) y Facione (2007), la educación especial cojea en los procesos de intercambio con el contexto circundante que permita a los estudiantes de educación especial llegar a observar y analizar desde su perspectiva especifica la forma como se desarrolla el contexto, hoy en día las salidas pedagógicas no se realizan, de acuerdo a la política rectoral, no se autorizan salidas de la institución educativa por seguridad de los estudiantes.

\section{Figura 5}

Influencia docente en el desarrollo de los procesos del pensamiento critico

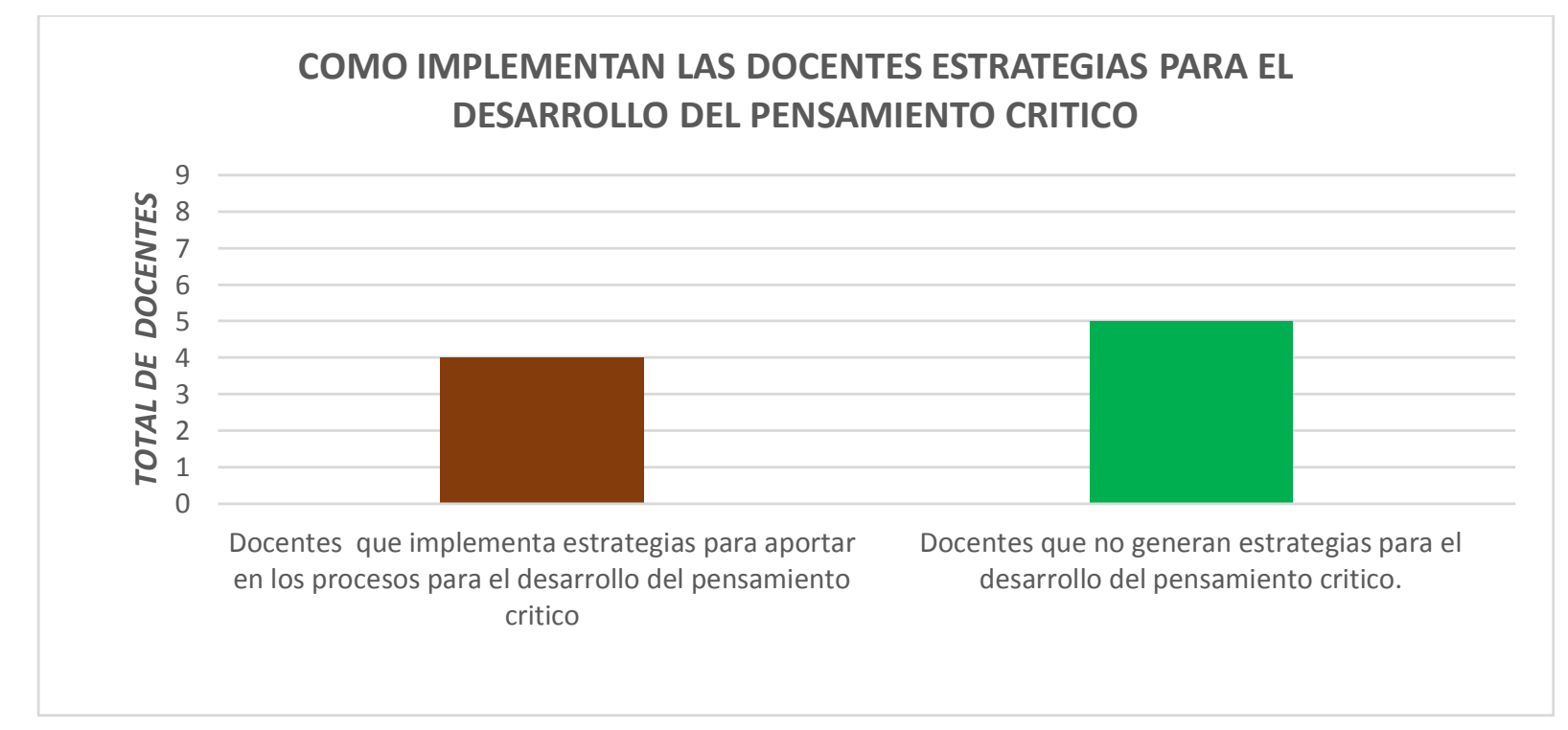

Fuente: Elaboración propia, a partir del instrumento de caracterización desarrollado en el proceso de investigación. Este instrumento se planteó teniendo en cuenta que una de las categorías de análisis corresponde a la implementación de estrategias pedagógicas para incentivas el desarrollo del pensamiento crítico en la población de educación especial. 


\section{INFLUENCIA DOCENTE EN EDUCACION ESPECIAL Y DESARROLLO INTEGRAL 60}

De acuerdo a lo referido por la docente Claudia "Nuestras actividades se desarrollaban de forma integral en unión con el equipo de apoyo; todas colaborábamos, trabajábamos e hicimos de este espacio un rincón de trabajo integrado donde teníamos cocina, 6 salones, baños y oficinas; el patio era un espacio pequeño donde disfrutaban al máximo los niños, pero nos sentíamos aisladas del resto de la escuela; poco a poco esto fue cambiando con mucho trabajo y sensibilizando a docentes y directores en lo que es un niño especial y hacernos valer por lo que somos".

Hace aproximadamente treinta (30) años, las personas que hacían parte de la educación especial en Bogotá, se encontraban enmarcadas en un contexto alienador y discriminatorio; las instituciones de educación se encontraban designadas como contextos de asistencialismo y cuidado; hoy en día la educación ha ido re direccionando la educación especial desde la mirada inclusivista a partir de la capacidades y habilidades que las personas de educación especial van desarrollando; es así como la historia del tiempo transcurrido por las docentes permite de alguna forma encontrar que la educación especial actual a pesar de no haber cambiado de forma significativa en los parámetros con los cuales se evalúa a la población que hace parte de este proyecto, sí ha cambiado en la manera de ver a los sujetos fuera del parámetro psicotécnico de los años mil ochocientos noventa y nueve.

Las dinámicas que se desarrollan en el proceso de enseñanza aprendizaje y el intercambio de experiencias entre estudiantes y maestras, genera en los niños, niñas y adolescentes, la posibilidad de desarrollar los elementos que acompañan el desarrollo del pensamiento crítico; para Vigotsky, Piaget, Davidov y Merani, desde el enfoque constructivista, refieren que los niños pueden llegar a plantear la necesidad de generar contexto de información e intercambio de experiencias; para ellos el pensamiento crítico contribuye a la al desarrollo personal y social y 
INFLUENCIA DOCENTE EN EDUCACION ESPECIAL Y DESARROLLO INTEGRAL 61

retomando a Mantilla (2001), la importancia del contexto escolar y social es permitir el escenario para reconocer y evaluar los factores que influyen en: nuestras actitudes y comportamientos.

La importancia de desarrollar personas con un pensamiento crítico abre el campo a la posibilidad de incentivar a las persona a realizar más preguntas y no aceptar las cosas en forma crédula sin un análisis cuidadoso en términos de evidencia, razones y su- posiciones. El niño o el adolescente crítico aprenden a hacer una lectura más personal y objetiva de la publicidad y la enorme avalancha de información transmitida a través de los medios masivos de comunicación, aprenden a dejar a un lado la paja informativa (Rodríguez, 2012).

Hoy en día el Ministerio de Educación y la Secretaría de educación del Distrito han ido re direccionando la educación especial desde la mirada inclusivista, a partir de la capacidades y habilidades que las personas de educación especial desarrollan; es así como la historia del tiempo transcurrido por las docentes, permite de alguna forma encontrar que la educación especial actual, a pesar de no haber cambiado de forma significativa en los parámetros con los cuales se evalúa a la población, sí ha cambiado la forma de ver a los sujetos, pues ha roto con el parámetro psicotécnico de 1899.

\subsection{El contexto de las aulas exclusivas y su relación con las habilidades para la vida y el desarrollo humano integral.}

En el proceso de entrevista se formuló la siguiente pregunta ¿Qué estrategias utiliza usted, para el desarrollo del pensamiento crítico en su salón de clase? Esta pregunta se formuló con el fin de identificar los elementos del contexto escolar y de la vida cotidiana que cada uno de los actores (estudiantes, docentes y equipo de apoyo), tenían en cuenta durante el desarrollo de los espacios de intercambio enseñanza aprendizaje. 


\section{INFLUENCIA DOCENTE EN EDUCACION ESPECIAL Y DESARROLLO INTEGRAL 62}

Frente a este aspecto de las nueve docentes y profesionales del equipo, solamente tres de ellas tienen en cuenta los problemas de la vida cotidiana para incentivar en los estudiantes la posibilidad de hacerse preguntas problemas, con el fin de generar propuestas de respuestas.

Las estrategias que las docentes utilizan para el desarrollo del pensamiento crítico en su salón de clase se encontraron las siguientes respuestas: la docente Liliana plantea que para el desarrollo del pensamiento crítico se puede implementar acciones "por medio de actividades que se realizan en grupo, como videos, cuentos, lecturas de historietas, pero más que todo sobre problemas que les pasa a ellos en su diario vivir"; la trabajadora social (T.S), plantea que para este proceso las actividades a realizar "depende de la edad mental, el grado, la edad cronológica y el desarrollo de pensamiento de los estudiantes"; sin embargo, no establece de forma clara cuáles son las estrategias que durante su experiencia ha elaborado con las y los estudiantes.

La docente Patricia, refiere al "juego, como una estrategia para romper los esquemas, y formas de aprendizaje"; frente a este aspecto en el desarrollo del juego los niños y niñas llegan a establecer parámetros, roles sociales, normas y roles entre otros, como lo plantean (García \& Bradasic, 2009). El pensamiento crítico hace parte de una de los conceptos planteados en las habilidades para la vida; así mismo, de la organización de los procesos psicológicos superiores, permitiéndole a las personas construir un lenguaje argumentativo frente a las diferentes situaciones cotidianas, llevando a la construcción de fundamentos dinámicos propositivos a nivel del lenguaje, las actuaciones y pensamiento el mismo.

Por otro la docente hace hincapié de la importancia de realizar actividades, "A través de trabajos en grupo, en equipo, incentivando una buena expresión y comunicación, desde lo concreto, lo lúdico y la vivencia de valores como el respeto, la solidaridad, la tolerancia y la equidad, valores que son los ejes fundamentales en el proyecto propuesto para este año permitiendo e incentivando la creatividad". 


\section{INFLUENCIA DOCENTE EN EDUCACION ESPECIAL Y DESARROLLO INTEGRAL 63}

De acuerdo a Romano (1995), Kurffis (1998) y Lipman, los escenarios cotidianos que sirven como estrategias para el desarrollo de este tipo de pensamiento, la posibilidad de resolver un problema, la toma de decisión, la formación de un concepto, la exploración deben servir como estrategias de la formación curricular, con el fin de aumentar los escenarios que lleven a los estudiantes de educación especial a construir desde la cotidianidad los elementos que hacen parte del desarrollo del pensamiento crítico, teniendo en cuenta que de acuerdo a las pautas establecidas por las profesionales y docentes de educación especial, este tipo de estrategias son muy limitadas en el contexto escolar de las aulas exclusivas.

El reto de la escuela es permitirle a los estudiosos implementar las enseñanzas teóricas en realidades y las realidades en la transformación de los seres humanos que hacen parte del contexto social y escolar.

Reconociendo y resignificando la importancia del contexto escolar, es definitivo reconocer que es este espacio el cual hace parte constante de la construcción de identidad, luego de la familia, así los estudiantes de educación especial pertenecientes a las aulas exclusivas, llegan a permearse de los diferentes intercambios, rutinas, afectos e imitaciones (esta última situación se presenta en un gran porcentaje de las personas con déficit cognitivo) Figueroa $(2016)^{6}$ contexto que de acuerdo a los estándares de educación debe permitirle a los estudiantes, preguntarse cuál es su papel en el día a día en la construcción de formas de pensamiento y de cambios en los procesos cognitivos Martínez (1999).

\footnotetext{
${ }^{6}$ Figueroa, P. Psicóloga aulas de educación especial jornada mañana Colegio Gustavo Restrepo, hace esta aclaración teniendo en cuenta que una de las características de los niños y niñas de educación es el aprendizaje por imitación.
} 


\section{INFLUENCIA DOCENTE EN EDUCACION ESPECIAL Y DESARROLLO INTEGRAL 64}

\subsection{El desarrollo del pensamiento crítico como una habilidad para la vida en la población perteneciente a las aulas exclusivas o aulas diferenciales}

De acuerdo al interés de la investigación durante el proceso de entrevistas se realizó a cada una de las docentes y profesionales del equipo de apoyo la siguiente pregunta ¿A los niños, niñas y adolescentes que pertenecen a estas aulas especiales se les enseña a buscar opciones para resolver algún tipo de problema para la vida diaria? Frente a este aspecto las docentes refieren que a los niños, niñas y a adolescentes de las aulas exclusivas, se les brindan las enseñanzas necesarias para que puedan enfrentar la vida; entre las respuestas tenemos las siguientes:

La docente Liliana hace referencia a la resolución de problemas que se presenten en su diario vivir; la docente Liliana refiere lo siguiente" Si, mediante la resolución de pequeños problemas en su vida escolar, cosas que les pasa en su diario vivir, en el descanso, en el salón, rutas etc.”.

La Trabajadora social frente a la pregunta ¿A los niños, niñas y adolescentes que pertenecen a estas aulas especiales se les enseña a buscar opciones para resolver algún tipo de problema para la vida diaria? "Si hasta donde es posible teniendo en cuenta: su coeficiente intelectual, su edad cronológica, los avances y evaluaciones pedagógicas, los factores presentes de salud, el contexto familiar que en el caso de nuestros estudiantes en su gran mayoría son familias de estrato 0,1 y 2 y por supuesto el ambiente social.

Es importante retomar las posturas de Mantilla (2005), quien plantea que las habilidades para vida se desarrollan a partir de los espacios implementados en el contexto escolar, la familia, los amigos, el contexto social desde la mirada de habilidades para la vida se generan a partir de espacios como la escuela y la familia que se logra así mismo en los estudiantes, a partir del expansión y mejoramiento de destrezas psicosociales que son necesarias para el fortalecimiento y la cimentación de procesos individuales, familiares, sociales, y comunitarios. Desde esta 


\section{INFLUENCIA DOCENTE EN EDUCACION ESPECIAL Y DESARROLLO INTEGRAL 65}

perspectiva las habilidades para la vida buscan el desarrollo y la promoción del desarrollo humano. Mantilla (2005).

Por tal razón y desde esta perspectiva los escenarios de los cuales hace parte el niño, niña y adolescentes permite concluir que las habilidades psicosociales y las habilidades para la vida que los estudiantes aprenden y desarrollan, les permite una construcción y expresión integral de su personalidad, así como hacer un excelente uso de los recursos subjetivos y éticos, así como de los recursos que hacen parte del contexto social.

Al realizar el planteamiento de una investigación que permita identificar la posibilidad del desarrollo del pensamiento crítico desde el marco de las habilidades para la vida en la población de educación especial se hace un llamado a revisar, los postulados como el de Lipman (1992) el cual busca incentivar y fortalecer las acciones y estrategias pedagógicas que permitan a los estudiantes y niños construir formas de ver, pensar y vivir el contexto que les rodea; al pensarse esta posibilidad en la población con déficit cognitivo, se generan grandes obstáculos tanto pedagógicos como sociales y políticos, la mirada aún cercana del idiota de 1886, ronda muchos de los espacios y no solamente los académicos, es por esta razón que el deber de la escuela y la familia se brindar en un saltarín que le dé al niño, niña y adolescente la posibilidad de vivir sin fuera de la sombra de un coeficiente intelectual, la enseñanza aprendizaje Torres (1996).De igual manera a incentivar en el contexto administrativo y pedagógico la posibilidad de generar un mayor acercamiento a los estudiantes frente al contexto real que le permita identificar su rol en la familia, la escuela, la sociedad, el contexto familiar y el contexto individual. 


\subsection{Entre el contexto escolar y el rol familiar en el desarrollo del pensamiento crítico de} los estudiantes pertenecientes a las aulas exclusivas o aulas diferenciales.

La familia y la escuela dos escenarios, dos contextos que circunda la vida y los proyectos de vida de los estudiantes, dos formas de interpretar el mundo y la vida, dos formas de enseñanza y un solo objetivo general, poder sacar a la sociedad seres humanos buenos, responsables y coherentes con la vida que llevan; hoy en día muchas de las estrategias del contexto escolar se han encaminado a la construcción de enseñanzas basadas en la experiencia y la realidad social Lipman (1992).

Por esta razón es significativo retomar la mirada que las docentes de educación especial han construido de la familia, la escuela y su relación con el desarrollo del pensamiento crítico, frente a este aspecto se realizó la siguiente pregunta: ¿Involucra en el proceso del desarrollo del pensamiento crítico a las familias de los niños, niñas y adolescentes que se encuentran a su cargo? ¿Porque?

Figura 6 Un espacio para el desarrollo del pensamiento crítico

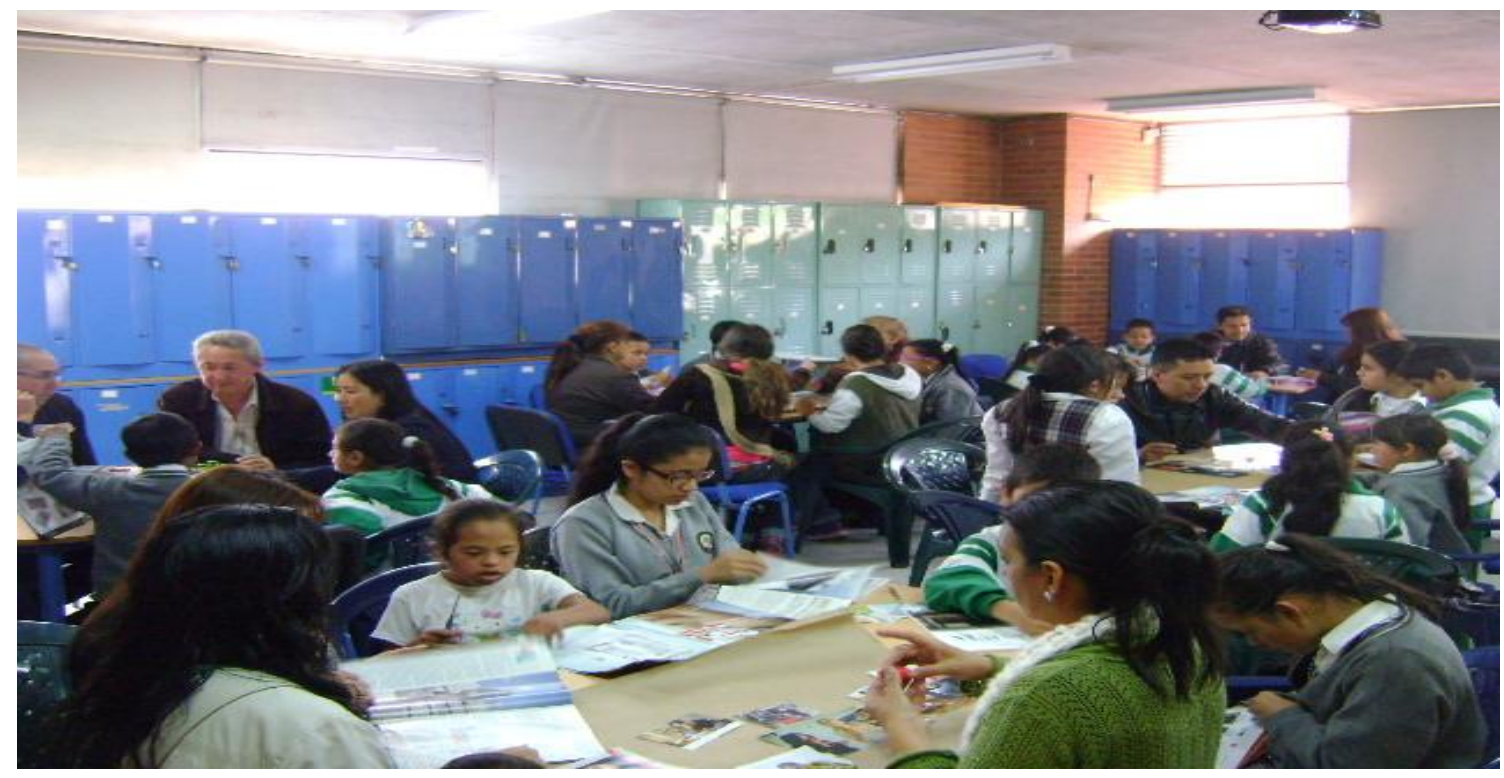

Fuente: Escuela de Padres. Colegio Gustavo Restrepo Sede C jornada mañana 2015. 


\section{INFLUENCIA DOCENTE EN EDUCACION ESPECIAL Y DESARROLLO INTEGRAL 67}

La docente Liliana, frente a esta pregunta refiere que; "Sí, porque es importante que haya una buena comunicación entre escuela familia para lograr un mejor desempeño en su vida integral"; en la dinámica escolar de educación especial, se presentan dos escenarios al interior del aula fuertes día a día Figueroa $(2015) ;{ }^{7}$ un escenario donde se encuentra el estudiante calmado que no pregunta, no responde y solamente actúa frente a la exigencia del contexto y el segundo escenario, el estudiante que pregunta, no se sienta, habla corre, sonríe y en palabras coloquiales, no pasa desapercibido; el ejemplo se encuentra relacionado ya que para el caso del segundo estudiante es necesario citar a la familia, y de acuerdo a Torres (1996), se irrumpe el escenario enseñanza aprendizaje, para contener la situación que irrumpe con la armonía.

De acuerdo a lo anterior hasta qué punto el contar con la familia se convierte en un límite para evitar en el estudiante realizar nuevas actuaciones y la construcción de nuevas miradas.

Para la Trabajadora Social Laura, la familia hace parte permanente de los comportamientos y rutinas del estudiante por eso frente a la pregunta ella responde: "Por supuesto, en lo que es posible, teniendo en cuenta primero que el estudiante es producto de unas relaciones, de unas personas que conforman su grupo familiar y que esto hace que tenga una historia de vida y que con ellos debe construir su propio proyecto que involucre todos los niveles: individual, grupal, laboral y social.

La importancia del trabajo con la familia se hace más urgente, teniendo en cuenta que su situación de discapacidad en muchas ocasiones lo lleva a que deba tener siempre el cuidado y protección de los miembros de su grupo familiar”. Retomando a Minuchin (1984), la familia, se ha constituido en la estructura y la estructura creída se apoya y valida los aspectos que se

\footnotetext{
${ }^{7}$ Figueroa. P, Psicóloga de educación especial sede C jornada mañana Colegio Gustavo Restrepo.
} 


\section{INFLUENCIA DOCENTE EN EDUCACION ESPECIAL Y DESARROLLO INTEGRAL 68}

entretejen a partir de las dinámicas de los actores que conforman este núcleo, la familia es un grupo céntrico de un contexto social, el cual permite con y desde sus integrantes el fortalecimiento de nuevas disposiciones sociales, culturales, académicas, vinculares, cognitivas y afectivas.

Así mismo la escuela de educación especial, permite validar los espacios de construcción de respeto, equidad, colaboración a partir de los proyectos institucionales y los cambios ideológicos así como de nuevos paradigmas que plantean enriquecer el significado del ser y no solamente del quehacer.

La docente Natalia plantea la importancia de la familia a partir de la siguiente respuesta: "Es fundamental involucrarlas pues son eje fundamental del proceso, es desde el entorno familiar que los niños adquieren experiencias y conocimientos que son base en el proceso educativo, pues como ya dije, dentro de este, se tienen en cuenta los aprendizajes previos y los distintos contextos en los que se desarrolla el estudiante. Es entonces importante darle a la familia las herramientas que ayuden a lograr que nuestros estudiantes aprendan a solucionar situaciones cotidianas y a tomar decisiones de una manera adecuada y acorde a sus posibilidades. Además la familia debe tener corresponsabilidad en el proceso educativo de su hijo o hija y apropiarse de su rol como primeros educadores".

Teniendo en cuenta el contexto de la familia como un factor que permea y facilita o limita las habilidades para la vida, en el espacio escolar desde el área de psicología de la sede C jornada de la mañana, se ha evidenciado por un lado la negación de uno o varios integrantes de la familia ya sea nuclear o extensa, frente a la condición cognitiva de su hijo, hija, sobrino, sobrina, nieta o nieto entre otros vínculos que se puedan encontrar en las dinámicas familiares de los estudiantes de educación especial. 
Por otro lado la dinámica unidireccional del colegio hacia la familia se ha venido fortaleciendo cada día más, quebrantado la presencia de la familia en el contexto escolar, generando más importancia sobre los niveles de actividad laboral y cultural, las citaciones a padres y madres de familia, se limitan desde la escuela, el ejercicio del área de trabajo social, se ha enmarcado en citar a la familia frente a la situación problema del estudiante dejándose a un lado la necesidad del estudiante, se requiere fortalecer a la familia como primer núcleo de socialización de los estudiantes de educación especial Minuchin (1984), una familia no sólo tiene estructura, sino un conjunto de esquemas cognitivos que legitiman o validan la organización familiar.

\subsection{La relación del déficit cognitivo y el obstáculo para el desarrollo del pensamiento crítico una mirada desde las docentes de educación especial}

Es importante reconocer y conocer la mirada de las docentes frente al desarrollo del pensamiento crítico en los estudiantes de educación especial, para este aspecto se realizó la siguiente pregunta. ¿Considera usted que los niños, niñas y adolescentes, que se encuentran a su cargo pueden llegar a desarrollar un pensamiento crítico en el contexto social del cual hacen parte?

La docente Liliana, responde lo siguiente: "No, ellos tienen un pensamiento muy inmediato que por su misma problemática no alcanzan a tener una mirada más amplia de su contexto, solo entienden cosas que pasan en el momento y después se olvidan. Algunos alcanzan a entender más que todo algunas situaciones familiares porque la viven a diario, pero otros no.

La Trabajadora social (T.S) frente a la posibilidad del desarrollo del pensamiento crítico en niños, niñas y adolescentes refiere lo siguiente: "Definitivamente NO, si tomamos definiciones 


\section{INFLUENCIA DOCENTE EN EDUCACION ESPECIAL Y DESARROLLO INTEGRAL 70}

como la de Siegel $\mathrm{H}^{8}$. Plantea que el pensador crítico es "una persona que actúa, evalúa, demanda y emite juicios basados en razones y que entiende y se conforma con los principios que gobiernan la evaluación de la fuerza de esas razones, se puede decir que una persona que piensa de forma crítica es aquella que posee: autonomía, curiosidad, coraje intelectual, empatía intelectual, perseverancia entre otros aspectos. Como primera medida tendría que determinarse hasta que estadio de pensamiento crítico es posible que llegue un estudiante con D.C., teniendo en cuenta que esto es un proceso que involucra todas las esferas de desempeño como ser humano, empezando con el desarrollo de pensamiento, de la ética, la moral, y sin desconocer que su discapacidad generalmente está asociada a otros diagnósticos, y que por consiguiente se requiere de tiempo y seguimiento muy, pero muy puntual desde su ingreso hasta el momento que terminan su preparación en talleres".

La docente Natalia, refiere ante la pregunta del desarrollo del pensamiento crítico en niños, niñas y adolescentes lo siguiente: “Sí, dependiendo de sus características individuales, de su entorno familiar y social inmediato y tomando el pensamiento crítico desde una forma de resolver las situaciones que su cotidianidad le presenta. Actualmente con el grupo de estudiantes que tengo sí. Además para este año desarrollamos en nuestra sede el proyecto: “construir paz es divertido" el cual está enfocado a “ empoderar a los niños y niñas con las habilidades, los conocimientos, las relaciones y las oportunidades que necesitan para ser constructores de paz a

\footnotetext{
${ }^{8}$ Siegel. H. Profesor de filosofía, universidad de Miami; Piensa que el pensamiento crítico se deriva del aumento vertiginoso de la información de la sociedad moderna, esto hace que los viejos métodos de información sean absolutos. Menciona que aprender se puede tratór como sinónimo de memorizar, aporta que el pensamiento crítico no es trascendental y vertical, sino horizontal y contextual. El adopta el término de bildung representando la controversia en relación del pensamiento crítico suponiendo que los seres humanos somos capases mediante el intelecto y la razón. Retoma el pensamiento crítico de Plantón además de ser considerado al autor de razonar como la facultad u "ojo" de alma que permite al individuo ascender el conocimiento y a definiciones universales. Recuperado de https://scholar.google.es/citations?user=slO6DWoAAAAJ\&hl=es\&oi=ao.
} 


\section{INFLUENCIA DOCENTE EN EDUCACION ESPECIAL Y DESARROLLO INTEGRAL 71}

través de actividades lúdicas" y que tiene como uno de los objetivos específicos el "desarrollar en los niños y niñas habilidades comunicativas asertivas con un lenguaje de paz, que le permita tomar decisiones , ser crítico y resolver problemas de su cotidianidad" Todo ello dependiendo de las posibilidades de cada uno de los niños y niñas”.

La docente Claudia, quien lleva más de treinta años de experiencia como docente de educación especial refiere que: "Los alumnos con nivel bajo no logran tener pensamiento crítico pero a través de preguntas, motivación durante la clase le ayudan, a la Reflexión, la participación, a fomentar más al grupo, a promover revisiones por pares y pueden alcanzar una adaptación social y conseguir aptitudes vocacionales que le permitan desenvolverse durante la adultez con cierta independencia".

La docente Gloria, quien lleva aproximadamente 30 años como docente de educación especial refiere ante la pregunta responde: "Me parece que en ellos, es muy difícil que puedan llegar a desarrollar un pensamiento crítico, ya que ellos no analizan, no llevan concepto de tiempo y se les olvida todo lo que se trabaja en clase”. De acuerdo a las respuestas anteriores se encuentra por un lado:

Las docentes de educación especial determinan el desarrollo del pensamiento crítico desde una perspectiva filosófica y no de habilidades para la vida; llevando con ello a ver el estudiante como un sujeto de cumplimiento de órdenes y no de construcción de realidades y vivencias, Alcaldía Mayor de Bogotá (2004).

De igual manera teniendo en cuenta las respuestas anteriores se establece una limitante de la discapacidad cognitiva, frente al rol en un contexto social, ya sea este familiar, laboral, político o individual, desde esta perspectiva las aulas diferenciales entran la revisión de construcciones y parámetros de los años 1886 (Ver cuadro 2) y no en el desarrollo y 
INFLUENCIA DOCENTE EN EDUCACION ESPECIAL Y DESARROLLO INTEGRAL 72

fortalecimiento de habilidades planteadas desde la teoría humanista, ecologista y cognitiva que se enmarca desde el proyecto de la Alcaldía Mayor de Bogotá (2004).

\subsection{La influencia docente en el desarrollo del pensamiento crítico en niños, niñas y adolescentes de aulas exclusivas educación especial, un aspecto del desarrollo humano integral.}

Es importante rescatar en la narrativa de la docente Trabajadora Social Laura, el significado que le da al rol de la familia y la escuela en el desarrollo humano integral de los estudiantes. De igual forma es interesante encontrar que si bien para la docente no hay un desarrollo del pensamiento crítico en los niños, niñas y adolescentes -teniendo en cuenta que ellos no presentan simpatía intelectual- lo que para ella es resolución de conflictos y análisis de las situaciones, refiere que la educación que se imparte en la escuela está direccionada al fortalecimiento de procesos psicosociales, socio afectivo, éticos y morales.

Retomando a Mantilla (1997), las habilidades para la vida, y en este caso del desarrollo del pensamiento crítico, no se enmarcan solamente en la capacidad de las personas para resolver las diferentes situaciones del diario vivir; en esencia este autor plantea que hablar de las habilidades para la vida permite a los seres humanos el auto reconocimiento, el desarrollo de valores y la apuesta de compartir con el mundo que le rodea.

Por otro lado, para la docente Liliana, el desarrollo del pensamiento crítico en niños y niñas de educación especial no se presenta; al respecto refiere que su pensamiento es muy inmediato. Sin embargo, cuando la docente responde las otras preguntas que guardan relación con el mismo tema, se halla que en la estrategia pedagógica trabajada en el salón de clase tiene en cuenta aspectos de la vida diaria con los estudiantes, con el fin de hacerlos reflexionar frente a las situaciones vividas, pero no existe claridad frente a la estrategia de desarrollo del 


\section{INFLUENCIA DOCENTE EN EDUCACION ESPECIAL Y DESARROLLO INTEGRAL 73}

pensamiento crítico. Retomando a Mantilla (1997), en el marco de las habilidades para la vida, este autor hace referencia a la importancia que adquiere el entorno donde los seres humanos socializan, destacando así mismo cómo la escuela permite al estudiante desplegar las destrezas psicosociales, requeridas en la construcción y consolidación de los procesos individuales, sociales, familiares y comunitarios.

La docente desarrolló procesos pedagógicos que podrían aportar al desarrollo del pensamiento crítico, pero que en el momento en que se desconoce o carece la intención del desarrollo de este proceso queda aislado del proceso educativo invisibilizando el sentido que tiene la escuela dentro de la enseñanza; en el momento en que la docente desconoce los procesos que se relacionan con el pensamiento crítico está perdiendo un campo fundamental dentro de los elementos formativos de los niños y las niñas.

Las aulas exclusivas se encuentran transversalizadas con la mirada de docentes que acompañan diariamente los procesos pedagógicos de los estudiantes al énfasis de su profesión; de acuerdo a este aspecto se encuentran posturas como la de la docente Claudia quien refiere el ejercicio pedagógico para el desarrollo del pensamiento crítico desde la lectura de "Cuentos, canciones, poesías, trabalenguas, juegos, crucigramas, sopa de letras etc. Y apoyándolos en el proyecto de aula conseguir la paz es divertido; de ahí parto para decir que con juegos propicio aprendizaje. Es una forma de expresión, implica participación activa, es espontáneo, libre, es fuente de alegría de placer y constituye a un continuo aprendizaje”.

Es necesario resaltar la importancia que tienen las estrategias didácticas y la integración curricular dentro de los procesos formativos, pues generan un proceso de aprendizaje para los niños y niñas que corresponde con el desarrollo de las habilidades a partir del contexto en el que viven. 


\section{INFLUENCIA DOCENTE EN EDUCACION ESPECIAL Y DESARROLLO INTEGRAL 74}

Otras docentes refieren el papel de las aulas exclusivas como espacios que brindan herramientas para la vida, las cuales son el aprendizaje de la lectoescritura, las operaciones matemáticas, la relación con las personas que se encuentran diariamente en los diferentes contextos, el cumplimiento de los parámetros y las normas del diario vivir; un ejemplo de ello es el ejercicio que refiere la docente Alejandra: "desde terapia del lenguaje, las actividades van encaminadas a desarrollar en lo posible procesos de abstracción del lenguaje, pensamiento, habilidades comunicativas a nivel de expresión oral del lenguaje, con el fin de que ellos narren, se expresen espontáneamente, logren conversar, tomar turnos, entender en lo posible el punto de vista del otro para responder”.

"Específicamente se realizan actividades donde los estudiantes deberán describir, diferenciar conceptos, definirlos teniendo en cuenta uso, clasificaciones y supra clasificaciones hasta donde el niño comprenda, actividades de reconocimiento de vocabulario, de análisis, síntesis, formular enunciados erróneos para que el estudiante identifique el error y lo corrija. En lo posible se lleva al proceso de deducir términos y situaciones de acuerdo al nivel cognitivo y al grupo a que pertenecen. Ya que estos están determinados por los adelantos en los procesos que llevan los estudiantes".

La docente Natalia considera que para lograr coadyuvar en el desarrollo del pensamiento crítico desde el aula, es importante utilizar estrategias “a través de trabajos en grupo, en equipo, incentivando una buena expresión y comunicación, desde lo concreto, lo lúdico y la vivencia de valores como el respeto, la solidaridad, la tolerancia y la equidad, valores que son los ejes fundamentales en el proyecto propuesto para este año permitiendo e incentivando la creatividad". 


\subsection{El rol de la escuela en el desarrollo del pensamiento crítico de niños, niñas y} adolescentes de aulas exclusivas.

El contexto de la escuela con el tiempo ha venido consolidándose como uno de los espacios determinantes, al igual que la familia, en el desarrollo humano integral de los estudiantes; es así como este espacio se ha transformado en el gran circuito de aprendizajes para confrontar la vida, construir con el otro y resolver las situaciones que la vida diaria presenta en determinados momentos.

El reto de la escuela es permitirle a los estudiosos implementar las enseñanzas teóricas en realidades y las realidades en la transformación de los seres humanos que hacen parte del contexto social y escolar. El contexto de la escuela hace parte constante del contexto en el cual comparten los estudiantes de educación especial pertenecientes a las aulas exclusivas, contexto que de acuerdo a los estándares de educación debe permitirle a los estudiantes preguntarse cuál es su papel diario en la construcción de formas de pensamiento y de cambios en los procesos cognitivos (Martínez, 1999, p.16).

Figura 7 De la teoría escolar a la realidad de vida

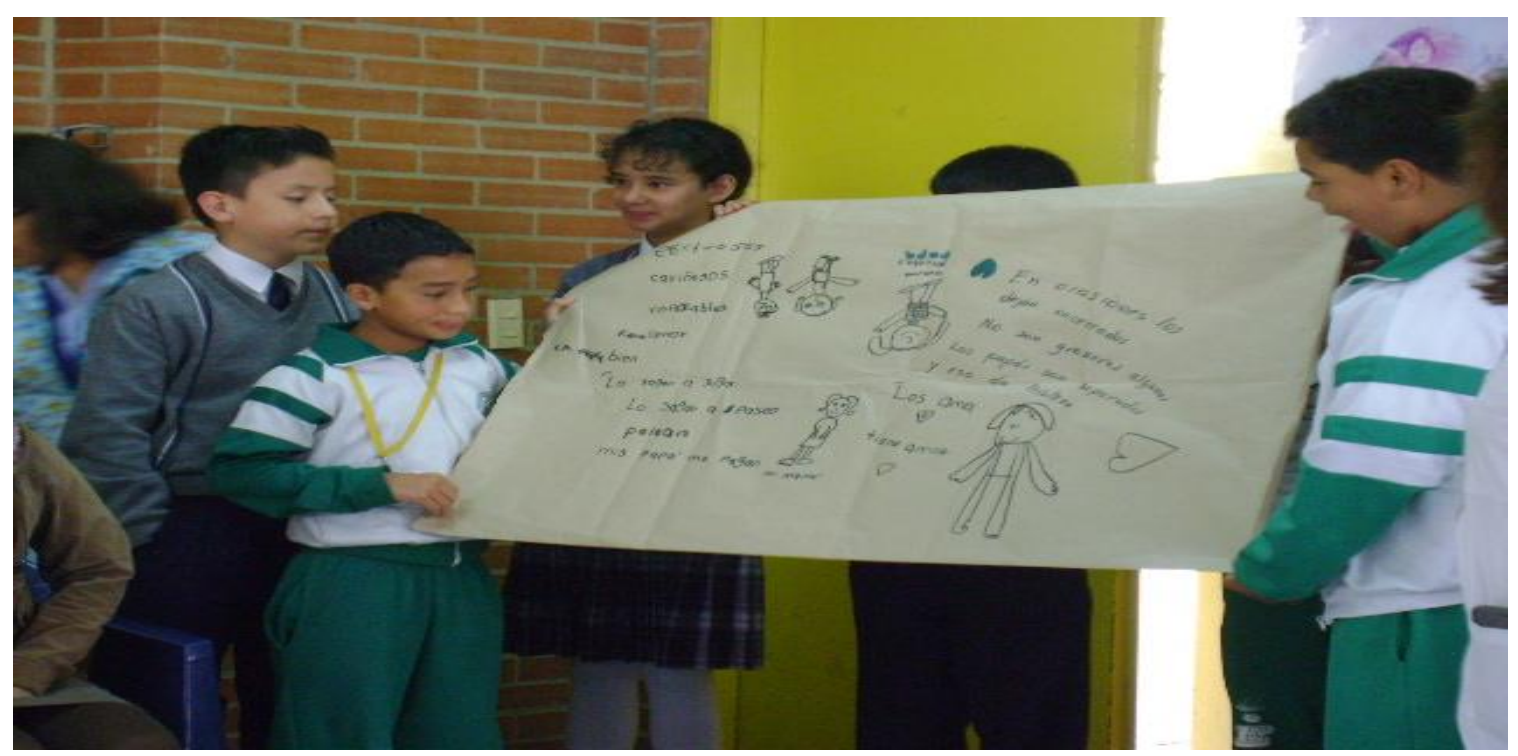


Fuente: Escuela de Padres. Colegio Gustavo Restrepo Sede C jornada mañana 2015.

Sin embargo, para las docentes de aulas exclusivas de la sede C, hasta ahora se están llevando a cabo capacitaciones direccionadas a un currículo que hable del desarrollo del pensamiento crítico en aulas exclusivas; si bien la escuela está planteando un nuevo horizonte, refiere la docente Liliana, "Es importante tener en cuenta primero que todo al niño con su problemática y direccionar así un plan curricular donde se involucren las dimensiones con las cuales trabajamos a diario, en cada dimensión diseñar una estrategia en el aula apropiada para el grupo".

\section{Figura 8}

Percepción docente la influencia del contexto educativo en el desarrollo del pensamiento crítico de niños, niñas y adolescentes de educación especial.

\section{INFLUENCIA DEL CONTEXTO EDUCATIVO EN EL DESARROLLO DEL PENSAMIENTO CRITICO}

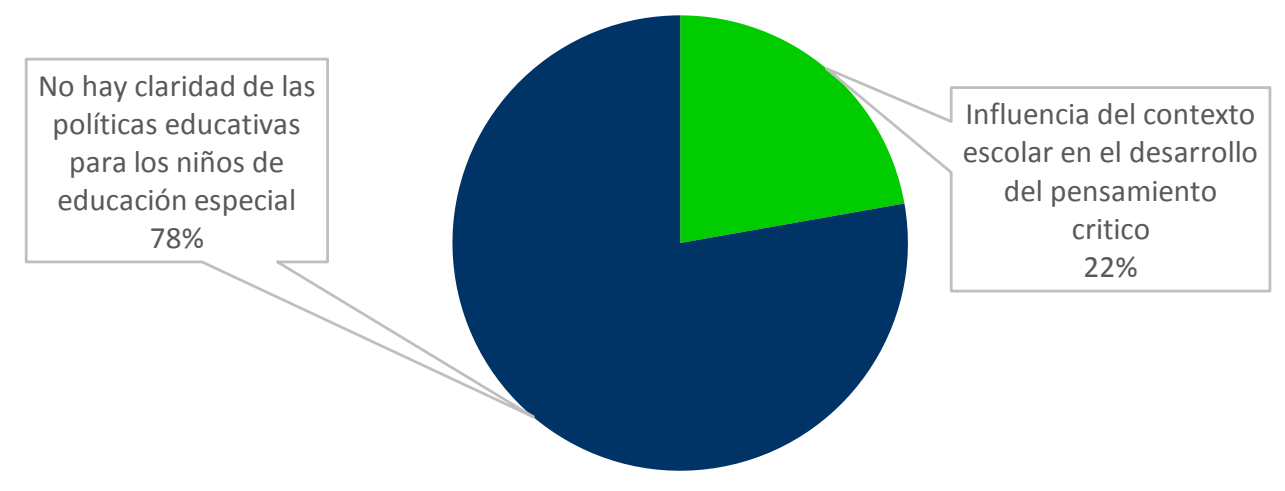

Fuente: Elaboración propia, a partir del instrumento de entrevista semiestructurada desarrollada en el proceso de investigación. En la investigación es significativo identificar y reconocer la relación entre la influencia del contexto educativo y los procesos de desarrollo del pensamiento crítico. 


\section{INFLUENCIA DOCENTE EN EDUCACION ESPECIAL Y DESARROLLO INTEGRAL 77}

Por otro lado la docente Patricia, en su diálogo refiere que los estudiantes no pueden desarrollar pensamiento crítico. Sin embargo, a la vez plantea que el desarrollo del pensamiento crítico y las habilidades para la vida son categorías que es importante trabajar con los niños y niñas, ya que de alguna forma les permite desarrollar la capacidad de analizar las "situaciones sencillas de su vida cotidiana"; teniendo en cuenta a Facione (2007), el espacio de intercambio de experiencias entre los estudiantes y los docentes es un diálogo de cuestionamientos y construcción de respuestas, preguntas y descripciones de las situaciones las cuales permiten al estudiante significar su contexto de aprehendizaje y experiencia social e individual. Estos elementos funcionan como los mínimos requeridos para los estudiantes de educación especial en aulas exclusivas, que conllevan a cada uno y una a gestionar elementos necesarios de análisis frente a las diferentes decisiones que de forma permanente están presentes en su contexto.

\subsection{La percepción del pensamiento crítico en las aulas exclusivas.}

La reflexión frente a la construcción del pensamiento crítico en los seres humanos viene resignificada por cada una de las teorías que se han fortalecido con las posturas tanto pedagógicas, como filosóficas, psicológicas, sociales y políticas; para los autores García y Bradasic (2009) el desarrollo del pensamiento crítico permite a los seres humanos, en la consolidación de los procesos básicos superiores, la construcción de un lenguaje argumentativo de acuerdo a las diferentes situaciones que se evidencian en la vida cotidiana, caracterizándose de esta forma un lenguaje propositivo en coherencia con las actuaciones.

En el desarrollo de las entrevistas con las docentes de las aulas exclusivas se encuentra una narrativa que toma distancia del desarrollo del pensamiento crítico en los estudiantes. Por un lado, para las docentes la proyección de vida de los estudiantes de estas aulas, son desesperanzadores en el contexto psicosocial, educativo, laboral y familiar entre otros aspectos 
y aunque la escuela se lee como un espacio de intercambio de experiencias, construcción de nuevos conocimientos, interrogantes como coadyuvadores en la solución de problemáticas de la vida.

Para cinco (5) de las docentes en los niños, niñas y adolescentes no se puede hablar del desarrollo del pensamiento crítico, enmarcando este aspecto en los límites del diagnóstico cognitivo.

La docente Laura hace referencia a las particularidades y las formas de ver el mundo por parte de los estudiantes; de acuerdo al dictamen emitido desde la entidad de salud "en general, la población con Déficit cognitivo presenta como particularidad aquella que le impone su diagnóstico", delimitando al diagnóstico las diferentes dimensiones caracterizadas en las habilidades para la vida y no a las posibilidades que los niños, niñas y adolescentes pueden ir descubriendo y redescubriendo en el contexto de la escuela, el salón de clase y en el intercambio de pensamiento con los compañeros de clase.

\section{Figura 9}

Percepción del desarrollo del pensamiento crítico las aulas exclusivas

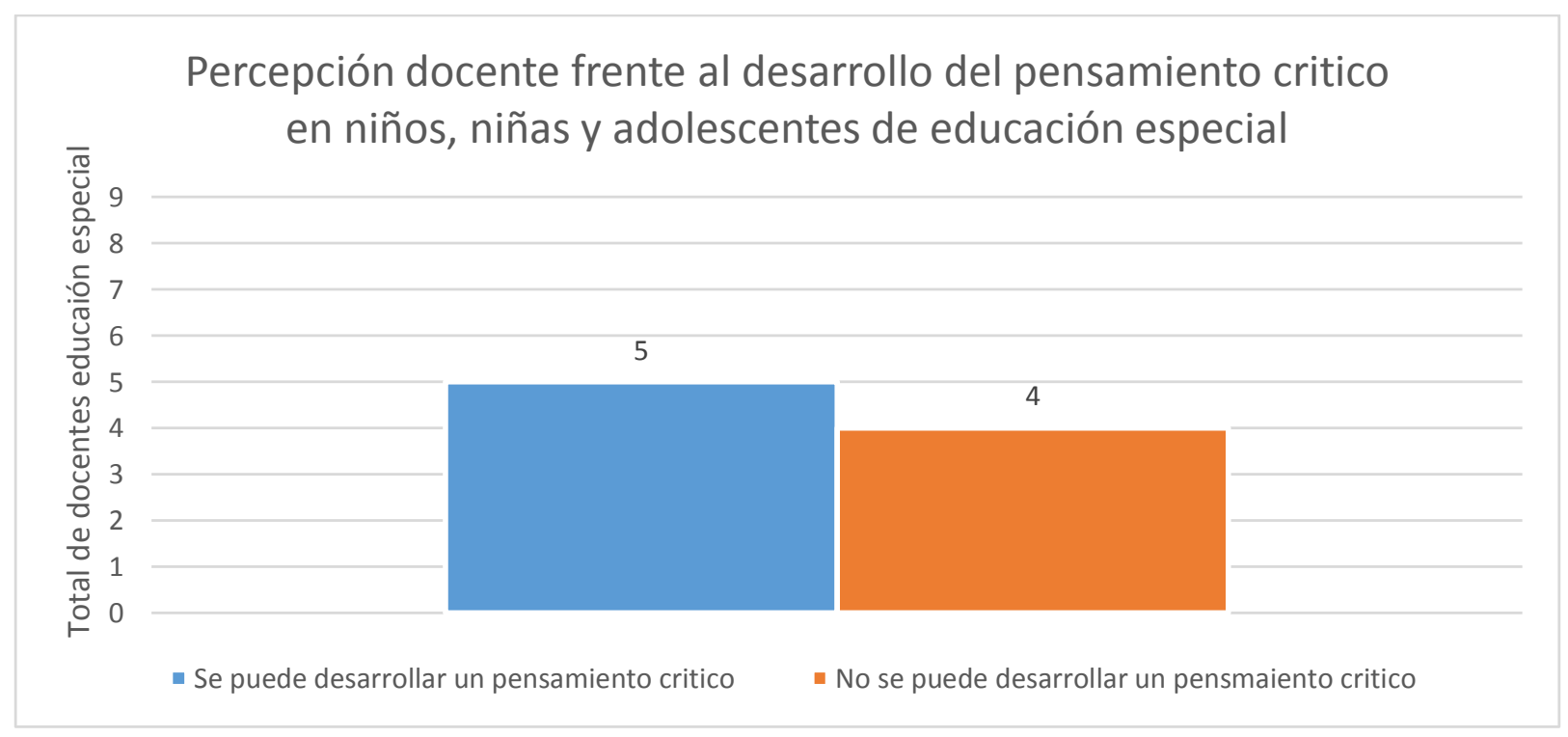




\section{INFLUENCIA DOCENTE EN EDUCACION ESPECIAL Y DESARROLLO INTEGRAL 79}

Fuente: Elaboración propia, a partir del instrumento de categorización construido en el desarrollo de la investigación. Estos resultados se encuentran a partir de la triangulación de las respuestas dadas por cada una de las docentes durante la entrevista a profundidad.

Por otro lado se encuentra que cuatro (4) docentes hacen referencia a la posibilidad del desarrollo del pensamiento crítico en los estudiantes, involucrando en el proceso que pueden hacer la escuela y las docentes a la familia y sus actores. La docente Alejandra plantea que "es importante involucrar a las familias de los niños, niñas y adolescentes en el desarrollo del pensamiento crítico, ya que aquellas son los responsables en primer lugar de estos; los padres es importante enterar del proceso educativo de su hijo; son los primeros formadores de sus hijos. De alguna forma también a ellos les sirve la instrucción para el mejor desempeño como familias".

Es así como al hablar de la percepción desde las docentes frente al pensamiento crítico, se pueden encontrar definiciones que se relacionan con el punto de vista de Jacques Piette (2001) citado por Díaz y Montenegro, quien plantea que el pensamiento crítico es un elemento fundamentalmente razonable desde un proceso cognitivo complejo donde predomina la razón. Es decir, para el caso de esta investigación en esta mirada el pensamiento crítico en los niños, niñas y adolescentes de las aulas exclusivas puede ser un sofisma de distracción. Así mismo se encuentran docentes que de alguna forma hacen referencia a la postura de Facione (2007), que plantea que el pensamiento crítico permite al ser humano abordar las situaciones que se presentan en el diario vivir, teniendo en cuenta el contexto en el cual se presentan y las diferentes alternativas que se pueden construir para la solución de la situación; "el pensamiento crítico es un pensamiento que tiene como propósito (probar un punto, interpretar lo que significa algo, resolver un problema), pero el pensamiento crítico puede ser una tarea colaborativa, no 
INFLUENCIA DOCENTE EN EDUCACION ESPECIAL Y DESARROLLO INTEGRAL 80

competitiva" (Facione, 2007, p.7). En el desarrollo del pensamiento crítico se están presentes habilidades y actitudes, las cuales se conocen como habilidades cognitivas y disposiciones. 


\section{INFLUENCIA DOCENTE EN EDUCACION ESPECIAL Y DESARROLLO INTEGRAL 81}

\section{CONCLUSIONES}

Los procesos pedagógicos que se implementan en las aulas de educación especial o aulas exclusivas, se han direccionados desde una pedagogía conductual, dejando a un lado una pedagogía que permita la potencialización de capacidades y habilidades para la vida.

Se requiere permitirle al estudiante acercarse a la realidad de su contexto, que se observé a sí mismo desde la diversidad, buscando con ello la construcción de una representación y un rol en el contexto que le rodea.

Los proceso pedagógicos en el contexto de educación especial han direccionados sus currículos a re encasillar a sus estudiantes, en el marco de una seudoeducación regular, fortaleciendo los currículos a la formación regular y no a una flexibilización curricular como se plantea la educación especial.

Dentro de la investigación que se realizó, no se encontraron documentos e investigaciones que plantearan el rol de la familia en la potencialización del pensamiento crítico. A lo largo de la indagación de la temática se encontraron evidencias de investigación que buscaban comprender el rol de la familia en el desarrollo emocional, enfoque psicosocial, desempeño escolar. Sin embargo, no se hallaron investigaciones que desarrollen el tema de la familia en el pensamiento crítico a partir del desarrollo humano integral.

A partir del desarrollo del pensamiento crítico se pueden fortalecer aspectos como la responsabilidad de los niños, niñas y adolescentes de educación especial, en tanto conduce al juicio porque se apoya en los criterios, es autocorrectivo y sensible a los contextos acordes a su forma de ver y construir su mundo. 


\section{INFLUENCIA DOCENTE EN EDUCACION ESPECIAL Y DESARROLLO INTEGRAL 82}

Las actividades planteadas en la mayoría de los grupos de aulas exclusivas, se direccionan hacia el desarrollo del pensamiento crítico (pregunta, resolución de problemas); sin embargo, este aspecto no es identificado como tal para las docentes.

Es posible desarrollar un pensamiento crítico en los niños, niñas y adolescentes de las aulas exclusivas, partiendo de la lectura de necesidades requerida para los estudiantes, reconociendo la importancia dela estimulación adecuada frente a la forma de ver el mundo desde la socialización en el contexto educativo.

El ejercicio para el pensamiento crítico en niños, niñas y adolescentes de las aulas, es importante abordar a partir de la excusa diaria de vida, es decir como plantea Facione (2007), el pensamiento crítico permite al ser humano abordar las situaciones que se presentan en el diario vivir, sin embargo en el caso de las aulas exclusivas es pertinente reconocer el contexto escolar, familiar a partir de la mirada única del estudiante de educación especial, para incitar en ellos la búsqueda de preguntas y respuesta a su realidad, a su concepto de vida.

Se encuentran brechas entre los procesos de cualificación docente y el tiempo de labor en las aulas exclusivas, las estrategias de enseñanza direccionadas al reconocimiento, identificación e intercambio del contexto educativo con el social, se encuentran sobre valoradas por el tipo de diagnóstico cognitivo que presente el niños, niña o adolescentes y no por las capacidades y habilidades que los estudiantes puedan llegar a desarrollar.

Desde el contexto de educación especial se desconocen los nuevos parámetros que se han establecido desde los manuales diagnósticos, buscando ver a los sujetos con discapacidades intelectuales a partir de las habilidades y capacidades que desarrollan en el entorno social, comunicativo e individual, es decir se plantea ver al estudiante de educación especial como un ser humano y no solamente ver al déficit. 


\section{INFLUENCIA DOCENTE EN EDUCACION ESPECIAL Y DESARROLLO INTEGRAL 83}

Retomando a Vygotsky y el fortalecimiento de las zonas de desarrollo próximo, es importante incentivar en los niños, niñas y adolescentes de las aulas exclusivas el intercambio de experiencias y vivencias fuera y dentro del contexto escolar. Esto con el fin de posibilitar en ellos el desarrollo de un pensamiento crítico a partir de su forma de ver e interpretar el mundo, enmarcado en la realidad social.

Teniendo en cuenta la postura desarrollada por Lipman frente a la necesidad de enseñar a los estudiantes procesos no solamente memorísticos, sino también de lectura crítica de la realidad social y cultural, es importante aclarar que si bien este teórico plantea la necesidad en estudiantes del aula regular, es importante incentivar en los estudiantes perteneciente a las aulas exclusivas la posibilidad de generar la pregunta teniendo en cuenta las particularidades de cada individuo. Así se abre la posibilidad de encontrar una respuesta a partir de los diferentes elementos que él o ella tengan para formular en el entorno tanto educativo como familiar, logrando con ello dar inicio a los procesos planteados por romano y Kurffis.

Permitir en aula de educación especial el desarrollo del pensamiento crítico, lleva a generar en los niños, niñas y adolescentes construcción de autonomía, rompiendo algunos aspectos de dependencia frente a la figura de la docente.

Es determinante revisar, los postulados como el de Lipman (1992), Torres (1996), Vygotsky (1982), Mantilla (20015) entre otros, los cuales buscan incentivar y fortalecer las acciones y estrategias pedagógicas que permitan a los estudiantes y niños construir formas de ver, pensar y vivir el contexto que les rodea, al pensarse esta posibilidad en la población con déficit cognitivo, se generan grandes obstáculos tanto pedagógicos como sociales y políticos, la mirada aún cercana del idiota de 1886 Tomado de Marchesi, A. (1999), ronda muchos de los espacios y no solamente los académicos, es por esta razón que el deber de la escuela y la familia en brindar un saltarín que le dé al niño, niña y adolescente la posibilidad de vivir sin la sombra 


\section{INFLUENCIA DOCENTE EN EDUCACION ESPECIAL Y DESARROLLO INTEGRAL 84}

de un coeficiente intelectual, sin la sombra de la irrealidad y por el contrario con la luz de la enseñanza aprendizaje Torres (1996).

Es afirmativa la posibilidad de forjar y despertar el interés en los niños, niñas y adolescentes de educación especial, lo que se requiere es abrir el abanico de posibilidades que existen en el gran contexto de la vida.

La relación entre el tiempo de servicio de las docentes y el rol que han venido desarrollando en el contexto de las aulas exclusivas les dificulta romper las dinámicas de la construcción frente al desarrollo humano integral en los niños con déficit cognitivo, restándole fuerza al ejercicio ciudadano que un gran porcentaje de ellos puede desempeñar, a partir de la pregunta frente a las situaciones de su diario vivir.

Es importante destacar que la escuela hace parte de uno de los contextos potencializadores del desarrollo humano integral así como la familia, la sociedad y la cultura entre otros; no obstante, en este estudio se encuentra que los aspectos de igualdad de oportunidades y la sostenibilidad de las mismas, como lo define el Programa de las Naciones Unidas (1995), está interrumpido por una gran brecha, combinada con la falta de herramientas administrativas, pedagógicas, e interdisciplinares etc., que deben articularse con las políticas públicas de educación, inclusión, discapacidad, infancia y adolescencia, familia, entre otros, con el fin de permitir en el ejercicio de la construcción de habilidades para la vida consolidar el rol de la escuela como dinamizador no solamente del pensamiento crítico sino del papel que pueden desempeñar los estudiantes que hacen parte de las aulas exclusivas en sus dinámicas sociales.

Las habilidades para la vida se encuentran enmarcadas en los derechos universales, este aspecto determina un más la importancia de hablar de procesos, que permitan reconocer las diferencias que se encuentran en el contexto actual, con el fin de lograr un generar y validar la humanización de la educación especial. 


\section{INFLUENCIA DOCENTE EN EDUCACION ESPECIAL Y DESARROLLO INTEGRAL 85}

El desarrollo del pensamiento crítico como una habilidad para la vida es una apuesta psicoeducativa, que busca significar al ser humano, más allá del argumento psicométrico que delimita su rol en el contexto social.

Aunque las habilidades para la vida hacen parte de los procesos del desarrollo humano integral y en este caso están enmarcadas en el desarrollo del pensamiento crítico, es importante que la docente Natalia educación especial, se pregunte diariamente ¿Cómo hacer para que mis estudiantes aprendan a pensar y vivir mejor?

Las habilidades para la vida desde su promoción tienen como eje centrar el fortalecimiento y la promoción de expresiones integrales de la personalidad y la individualidad en los seres humanos, por tal razón es importante ver a los niños, niñas y adolescentes como seres humanos y no simplemente como un ser vivo del entorno Mantilla (1997).

El desarrollo humano integral entre otros aspectos, considera determinante identificar y reconocer el rol que cada actor social desarrolla en el contexto del cual hace parte, comprendiendo en él sus potencialidades, particularidades y habilidades; durante esta investigación se logra dilucidar la dificultad para ver a los niños, niñas y adolescentes de las aulas exclusivas como seres sociales que hacen parte integral de la construcción de acuerdos, ejercicios de participación, intercambio de ideas y experiencias alineando de alguna forma su ejercicio en el marco de los derechos y las habilidades para la vida.

El desarrollo del pensamiento crítico como una habilidad para la vida es una apuesta psicoeducativa, que busca significar al ser humano, más allá del argumento psicométrico que delimita su rol en el contexto social. 


\section{INFLUENCIA DOCENTE EN EDUCACION ESPECIAL Y DESARROLLO INTEGRAL 86}

\section{RECOMENDACIONES}

Se requiere consolidar acciones continuas desde un aprendizaje significativo (rutinas pedagógicas) que coadyuven en el desarrollo del pensamiento crítico de los estudiantes partícipes de las aulas exclusivas.

Direccionar una política publica en educación especial con estrategias pedagógicas y metodológicas, que permitan ambientes de enseñanza direccionados al desarrollo de habilidades y capacidades para la vida

Aunque se hable de educación especial con déficit cognitivo, es importante resaltar la importancia de trabajar con ellos, en ellos y sus familiares acciones encaminadas a mejorar la perspectiva y esperanza de vida en los diferentes escenarios donde los niños, niñas y adolescentes de educación especial pueden ser parte.

Las narrativas de los estudiantes de las aulas exclusivas son muestra vital de los significados tejidos por ellos desde la escuela. Esta experiencia educativa permite la adquisición del aprehendizaje y las diferentes formas de pensar e indagar desde la vida cotidiana, convirtiéndose en los elementos fundamentales para el desarrollo del pensamiento crítico en los niños, niñas y adolescentes.

Desarrollo de una práctica educativa encaminada al énfasis de la educación integral, a partir de un currículo desde las necesidades de los estudiantes, trabajando en el proceso armónico de las personalidades, capacidades y habilidades individuales.

Es necesario enseñarle a pensar a los niños, niñas y adolescentes de las aulas especiales, teniendo en cuenta las situaciones individuales del gran universo cognitivos y su forma real del ver el mundo. 


\section{INFLUENCIA DOCENTE EN EDUCACION ESPECIAL Y DESARROLLO INTEGRAL 87}

Las docentes son quienes pueden llegar a direccionar estrategias pedagógicas y metodológicas, que permitan ambientes de enseñanza direccionados al desarrollo de habilidades y capacidades para la vida.

Es necesario brindar, desde las políticas administrativas y la escuela, escenarios de capacitación frente a las posturas teóricas que plantean el desarrollo del pensamiento crítico como categoría de las habilidades para la vida en los niños, niñas y adolescentes con déficit cognitivo. El propósito es generar estrategias adecuadas que les posibilite a los estudiantes asistentes a las aulas exclusivas construir desde el acompañamiento familiar y escolar un proyecto de vida, no solamente en la rutina ocupacional, sino también en el ejercicio de los derechos y deberes que hacen parte del desarrollo humano integral.

Las actividades diarias encaminadas al análisis, la pregunta y la respuesta, permiten la consolidación de los procesos requeridos para transformación del pensamiento en los niños, niñas y adolescentes de las aulas exclusivas.

Las aulas exclusivas son espacios de socialización que permiten a las docentes implementar actividades de construcción e identificación de los precurrentes necesarios en los estudiantes para el desarrollo del pensamiento crítico y su relación con las habilidades para la vida.

La estrategia psicopedagógica, teniendo en cuenta la mirada de habilidades para la vida en concordancia con el desarrollo del pensamiento crítico en los niños, niñas y adolescentes de las aulas exclusivas, debe ir más allá de escenarios memorísticos. Es necesario permitirle a esta población la capacidad de razonar, inferir, deducir, relacionar y elaborar síntesis a partir de sus capacidades y habilidades.

Asimismo, es menester construir una herramienta desde un modelo psicopedagógico, que permita fortalecer en los niños, niñas y adolescentes que hacen parte de las aulas exclusivas, las 


\section{INFLUENCIA DOCENTE EN EDUCACION ESPECIAL Y DESARROLLO INTEGRAL 88}

habilidades y procesos del pensamiento crítico, susceptibles de facilitar el desarrollo de habilidades para la vida y su participación en los diferentes escenarios del contexto.

Se requiere desarrollar un currículo FLEXIBLE para aulas exclusivas, que permita en el espacio del aula incentivar habilidades en los niños, niñas y adolescentes, de acuerdo a la época y tiempo en el cual se esté trabajando.

Es imperativo continuar fortaleciendo la idea de la importancia de desarrollar un pensamiento crítico en los niños y niñas perteneciente a las aulas exclusivas, encaminado a la argumentación, explicación y sustentación de soluciones, miradas y acciones, involucrando la mirada de docentes, administrativos y estudiantes; a partir de allí, fortalecer las habilidades para la vida desde la consolidación del pensamiento crítico.

Las propuestas metodológicas para el desarrollo del pensamiento crítico en los estudiantes de aulas exclusivas deben ser coherentes, consistentes y direccionadas a partir de las necesidades del grupo.

Es importante reconocer que aunque el niño, niña o adolescente presenta una memoria a corto plaza, los procesos de aprendizaje significativo durante el proceso de enseñanza aprendizaje, lleva mejorar los procesos de memoria a largo plazo; es decir pueden recordar aspectos sociales y material teórico en un plazo mayor que el actual.

El desarrollo del pensamiento crítico no se puede plantear solamente desde una perspectiva única de procesos psicológicos superiores. Esta forma de pensamiento debe estar circunscrita en la búsqueda de una verdad para reconocer los diferentes matices de la vida entre lo justo, verdadero y lo real sin convertirse en algo fortuito o improcedente.

Se requiere plantear actividades que permitan a los docentes reconocer las etapas para desarrollar el pensamiento crítico en los niños, niñas y adolescentes, con el fin de fortalecer las destrezas adquiridas a partir de las etapas de observación y percepción del mundo. 
INFLUENCIA DOCENTE EN EDUCACION ESPECIAL Y DESARROLLO INTEGRAL 89

\section{FUENTES BIBLIOGRÁFICAS}

Asociación Americana de psiquiatría. Manual Diagnostico y estadístico de los trastornos mentales DSMV. Arlington, VA, Asociación Americana de psiquiatría, 2014.

Barroso, R.C. (2012). Los instrumentos de la investigación acción participativa. La caja de herramientas. Tomado de www.

Berenstein, I. (1992). Psicoanalizar una familia. Buenos Aires: Editorial Paidós.

Berger, P., Luckmann, T. (2001). La Construcción Social de la realidad. Buenos Aires: Amorrortu Editores.

Boisvert, J. (2004). La formación del pensamiento crítico: teoría y práctica, Colección Educación y Pedagogía Educación y Pedagogía Series; Sección dos obras de Educación y Pedagogía, México: Edición Fondo de Cultura Económica.

Carrillo, B. (2009). Importancia del currículum oculto en el proceso de enseñanza-aprendizaje. Revista digital innovación y experiencias educativas, 14, Recuperado el 30 de Enero de 2016 de http://curriculumocultoenlaescuela.blogspot.com.co/2012/04/normal-0-21-false-falsefalse.html.

Casarini, M. (1997). Teoría y diseño curricular, México. Editorial Trillas. 
INFLUENCIA DOCENTE EN EDUCACION ESPECIAL Y DESARROLLO INTEGRAL 90

Castellano, H. (2007). El Pensamiento Crítico en la escuela, Buenos Aires, Argentina. Edición Prometeo.

Castejón, J. y Navas, L (2000). Unas bases psicológicas de la educación especial, España: Editorial Club Universitario.

Colectivo Docente de la ENSA. (2009). El Modelo Pedagógico: Constructivismo Socio Crítico; (Serie de documentos de divulgación). Acacias, Colombia.

De Bogotá, A.M. (2011).Política pública de Infancia y Adolescencia en Bogotá DC 2011-2021.

Díaz, L., y Montenegro, M. (2010). "Las Prácticas Profesionales y el desarrollo del pensamiento crítico". Presentado en el XXXII Simposio de Profesores de Práctica Profesional de Argentina. $\begin{array}{lllllll}\text { Recuperado el } & 07 & \text { de } & \text { Octubre } & \text { de }\end{array}$ http://www.econ.uba.ar/www/institutos/contable/ceconta/Foro_practica_profesional/Principal/P DF_Simposio_2010/T_2010_06_Diaz_Montenegro.pdfemas

Facione, P. (2007). Pensamiento crítico: ¿Qué es y porqué es importante? Recuperado el 28 de Agosto de 2014, de http://www.eduteka.org/PensamientoCriticoFacione.php.

García, A. V., y Bradasic, O. (2009). Los dominios del pensamiento crítico: una lectura desde la teoría de la educación. Teoría de la Educación, 21, 19-44. Recuperado el 07 de Octubre de 2014. http://campus.usal.es/ revistas_trabajo/index.php/1130-3743/article/viewFile/7150/7215 
INFLUENCIA DOCENTE EN EDUCACION ESPECIAL Y DESARROLLO INTEGRAL 91

Gómez, J., y Salamanca, L. (2008). Desarrollo del pensamiento crítico como estrategia para incentivar habilidades sociales en los niños y niñas de 5 a 6 años. (Tesis de Pregrado) Universidad de la Sabana, Bogotá, Colombia.

Illescas, J. (2011). Habilidades para el desarrollo del pensamiento crítico en el currículo del primer año. (Tesis de Maestría). Repositorio institucional Universidad de Cuenca, Ecuador.

Lipman, M. (1992). Filosofía en el aula. Recuperado el 7 de enero de 2015 en http//www.redalyc.org/articulo.oa?id=170121560006.

Mantilla, L. (2001). Habilidades para la vida: Una propuesta educativa para la promoción del desarrollo humano y la prevención de problemas psicosociales. Recuperado el 23 de Agosto de 2014 de https://es.scribd.com/doc/97158108/Habilidades-para-la-Vida-Fe-y-Alegria-Una-propuestaeducativa-para-la-promocion-del-desarrollo-humano-y-la-prevencion-de-problemaspsicosociales

Mantilla, L. (2005). Habilidades para la vida. Una propuesta de educativa para convivir mejor. Revista del instituto de investigaciones Educativas, año 9. № 16 Diciembre 2005, Recuperado el 20 de $\begin{array}{llll}\text { Agosto } & \text { de } & 2014 & \text { de }\end{array}$ http://revistasinvestigacion.unmsm.edu.pe/index.php/educa/article/view/5637.

Marchesi, A. (1990). Del lenguaje de la deficiencia a las escuelas inclusivas. Trastorno del desarrollo y necesidades educativas especiales. 3, 21-44. Recuperado el 20 de Octubre de 2015 de http://dialnet.unirioja.es/servlet/articulo?codigo=2089561. 
INFLUENCIA DOCENTE EN EDUCACION ESPECIAL Y DESARROLLO INTEGRAL 92

Márquez, M. (2004). El desarrollo humano desde la perspectiva integral y su proyección mundial. La Habana: Cátedra UNESCO de Desarrollo Humano Sostenible. Recuperado el 23 de Septiembre de 2015 de https://scholar.google.com.co/scholar?lookup=0\&q=m\%C3\%A1rquez+2004+desarrollo\&hl=es $\underline{\text { \&as_sdt }=0,5 \& \text { as_vis }=1}$

Martínez, A. (2007). La observación y el diario de campo en la definición de un tema de investigación. Revista electrónica Institución Educativa los libertadores, 1, 10-24 Recuperado el 11 de Febrero de 2015

de http://www.ulibertadores.edu.co:8089/recursos_user/documentos/editores/7118/9\%20La\%20ob servaci\%F3n\%20y\%20el\%20diario\%20de\%20Campo\%20en\%20la\%20Definici\%F3n\%20de\% 20un\%20Tema\%20de\%20Investigaci\%F3n.pdf.

Martínez, M. (1999). El enfoque Sociocultural en el estudio del desarrollo en la educación. Revista electrónica de investigación educativa, 1, 1 Recuperado el 21 de Octubre de 2014 de http://redie.ens.uabc.mxlvol1no1 lcontenido-mtzrod.html.

Minuchin, S. (1984). Técnicas de Terapia Familiar. España: Paidós.

Moromizato, R. (2007). El desarrollo del pensamiento crítico creativo desde los primeros años. Universidad de San Buenaventura, seccional Medellín Vol. 7, N². Visita miércoles 27 de agosto del 2014. Recuperado de http://bdatos.usantotomas.edu.co. 
INFLUENCIA DOCENTE EN EDUCACION ESPECIAL Y DESARROLLO INTEGRAL 93

Organización Panamericana de la Salud. (2001). Enfoque de habilidades para la vida para un desarrollo saludable de niños y adolescentes.

Pachón, X. (2007). La familia en Colombia a lo largo del siglo XX. Puyana, Yolanda y Ramírez María Himelda, editoras. Familias, Cambios y Estrategias. Bogotá: Universidad Nacional de Colombia, Facultad de Ciencias Humanas, Alcaldía Mayor de Bogotá, 157-158.

Programa de la Naciones Unidas, (PNUD). (1995). Informe sobre desarrollo humano 1995. Recuperado el 23 de Octubre de 2014, de http://hdr.undp.org/es/content/informe-sobre-desarrollo-humano$\underline{1995}$

Rodríguez, M. (2012). Lógica: Pensamiento crítico para el uso diario. Boletín Científico Sapiens Research, Vol. 2 (1). Visita jueves 11 de Septiembre del 2014. Recuperado http://www.sapiensresearch.org/.

Ruiz, C. (2006). El papel de la familia en la Transmisión sociocultural y de la salud mental, España: Editorial Red nómadas.

Samper, L. (2000). Familia, Cultura y Educación, Madrid: Edición de la Universidad de Lleida

Secretaria de Educación Distrital (2010). Reorganización curricular por ciclos, referentes conceptuales y metodológicos, Bogotá: Imprenta Nacional de Colombia. 
INFLUENCIA DOCENTE EN EDUCACION ESPECIAL Y DESARROLLO INTEGRAL 94

Secretaria de Educación Distrital, (2005). Para el Niño Diferente, Modalidad educativa de atención exclusiva para escolares con deficiencia cognitiva en colegios distritales. Educación incluyente. Bogotá Recuperado el 21 de Febrero de 2015 de https://scholar.google.com.co/scholar?biw=1366\&bih=634\&psj=1\&bav=on.2,or.r_cp.\&bvm=b $\underline{\text { v.112064104,d.dmo\&dpr=1\&um=1\&ie }=U \text { UTF- }}$

8\&lr\&q=related:byiWhsu0uhaJDM:scholar.google.com/

Secretaria de Educación Distrital, (2004). Serie: Culturas Incluyentes Escolares, Cuaderno de Trabajo de Bogotá. Recuperado el 17 de Febrero de 2015 http://sedbogota.edu.co

Sen, A. (2000). Desarrollo como libertad. Madrid: Editorial Planeta.

Sistemas educativos nacionales: Colombia, (1996). Organización de Estados Iberoamericanos para la Educación, la ciencia y la cultura.

Sumaza, C. R., y Rodríguez, T. (2003). Un análisis del concepto de familia monoparental a partir de una investigación sobre núcleos familiares monoparentales. Papers: revista de sociología, (69), 5982. Recuperado el 11 de $\quad$ Octubre $\quad$ de $\quad 2014$ http://ibdigital.uib.es/greenstone/collect/portal_social/index/assoc/gencat00/82.dir/gencat0082. pdf

Torres, J. (1996). El currículo oculto. (8va ed.). Madrid: Ediciones Morata. 
INFLUENCIA DOCENTE EN EDUCACION ESPECIAL Y DESARROLLO INTEGRAL 95

Vásquez, L. (2010). Actitud y pensamiento crítico. La problematización de los contextos en la construcción del conocimiento. Actualidades Pedagógicas Universidad de la Salle. (60). $\begin{array}{lllllll}\text { Recuperado el } & \text { jueves } & 21\end{array}$ http//revistas.lasalle.edu.co/index.php/ap/article/view

Viché, M. (2007). La educación sociocultural. Recuperado el 15 de Mayo de 2014, de http://www.quadernsanimacio.net/marioviche/edusocicul.pdf

Vygotsky, L. (1982). Historia del desarrollo de las funciones psíquicas superiores. Obras escogidas Tomo III. Recuperado el 11 de diciembre de 2015, de www.papelesdesociedad.info/IMG/.../vygotsky-obras-escogidas-tomo-3.pdf 
INFLUENCIA DOCENTE EN EDUCACION ESPECIAL Y DESARROLLO INTEGRAL 96

\section{FUENTES ORALES}

Buitrago, Sofía. (2015) Docente de educación especial Colegio Gustavo Restrepo Sede C, José Acevedo y Gómez jornada mañana

Castro, Gladys. (2015) Docente de educación especial Colegio Gustavo Restrepo Sede C, José Acevedo y Gómez jornada mañana.

Corredor, Beatriz. (2015) Trabajadora Social de educación especial Colegio Gustavo Restrepo Sede C, José Acevedo y Gómez jornada mañana.

Figueroa, Ángela. (2015) Terapeuta de Lenguaje de educación especial Colegio Gustavo Restrepo Sede C, José Acevedo y Gómez jornada mañana.

Figueroa, Islena (2015) Psicóloga de educación especial Colegio Gustavo Restrepo Sede C, José Acevedo y Gómez jornada mañana.

Gaitán, Marcela. (2015) Docente de educación especial Colegio Gustavo Restrepo Sede C, José Acevedo y Gómez jornada mañana.

Medina, Victoria. (2015) Docente de educación especial Colegio Gustavo Restrepo Sede C, José Acevedo y Gómez jornada mañana.

Osorio, Natalia. (2015) Docente de educación especial Colegio Gustavo Restrepo Sede C, José Acevedo y Gómez jornada mañana.

Pugliese, Orieta. (2015) Docente de educación especial Colegio Gustavo Restrepo Sede C, José Acevedo y Gómez jornada mañana.

Romero, Clemencia. (2015) Docente de educación especial Colegio Gustavo Restrepo Sede C, José Acevedo y Gómez jornada mañana. 